“IT'S EASIER TO BE WITH THEM": HOW CHILDREN WITH MENTAL HEALTH CONCERNS PERCEIVE THEIR EXPERIENCES WITH EQUINE-ASSISTED THERAPIES

\author{
By \\ Erin Harvey, B.A., Ryerson University, 2018 \\ An MRP \\ Presented to Ryerson University \\ In partial fulfillment of the requirements for the degree of \\ Master of Arts in the program of \\ Early Childhood Studies
}

Toronto, Ontario, Canada, 2019

(C) Erin Harvey 2019 
AUTHOR'S DECLARATION FOR ELECTRONIC SUBMISSION OF AN MRP

I hereby declare that I am the sole author of this MRP. This is a true copy of the MRP, including any required final revisions.

I authorize Ryerson University to lend this MRP to other institutions or individuals for the purpose of scholarly research.

I further authorize Ryerson University to reproduce this MRP by photocopying or by other means, in total or in part, at the request of other institutions or individuals for the purpose of scholarly research.

I understand that my MRP may be made electronically available to the public. 


\begin{abstract}
"It's easier to be with them": How children with mental health concerns perceive their experiences with equine-assisted therapies

Master of Arts, 2019

Erin Harvey

Program of Early Childhood Studies, Ryerson University
\end{abstract}

Animal assisted therapy was founded as early as 1792 to support an individual's health (Wilson, Buultjens, Monfries \& Karimi, 2017). One form of animal assisted therapy drawing attention over the past few decades is equine-assisted therapy and interventions (EAT/I). Research in this area has largely considered adults' perspectives of EAT/I and has failed to consider how children using EAT/I perceive treatments. Using a sociology of childhood framework (Prout \& James, 1997), a children's rights perspective (Di Santo \& Keannelly, 2014), and a disability justice framework (Devlieger, 1999) the present research employed qualitative, semi-structured interviews with open-ended questions and play-based methods. Five children aged five to twelve were interviewed, each of whom were enrolled in EAT/I. The findings demonstrated the children's appreciation for their experiences with horses and experiences at the farm. They provided insight into how EAT/I benefit them and contrasted these experiences to their lived experiences outside the farm.

Keywords: Equine assisted therapy, sociology of childhood, children's rights, mental health 


\section{ACKNOWLEDGEMENTS}

The following people were integral to the completion of this research. Thank you for supporting me during this journey.

First and foremost, thank you to all the participants for sharing your stories. To Patrizia Albanese for your patience, guidance, and for always supporting me. Your motivation and spirit inspire me always. To Aurelia Di Santo for all your help and for fighting for the good of children everywhere. To Jack, Owen, and Adi without whom I would not be here. To my family and friends for all your love, understanding, and patience. 


\section{DEDICATION}

This work is dedicated to William Harvey, who worked hard every day to ensure a formal education would be an option for future generations. To Lydia, my inspiration and my angel. To all the non-human beings that give us joy, acceptance, and unconditional love. 


\section{TABLE OF CONTENTS}

$\begin{array}{ll}\text { Chapter 1. Introduction } & \text { Page } 1\end{array}$

$\begin{array}{ll}\text { Chapter 2. Literature Review } & \text { Page } 6\end{array}$

Chapter 3. Theoretical and Conceptual Frameworks Page 19

$\begin{array}{ll}\text { Chapter 4. Methodology } & \text { Page } 26\end{array}$

$\begin{array}{lr}\text { Chapter 5. Findings and Analysis } & \text { Page } 36\end{array}$

$\begin{array}{ll}\text { Chapter 6. Discussion } & \text { Page } 55\end{array}$

$\begin{array}{ll}\text { Chapter 7. Conclusion } & \text { Page } 63\end{array}$

$\begin{array}{lr}\text { Appendices } & \text { Page } 64\end{array}$

$\begin{array}{ll}\text { References } & \text { Page } 91\end{array}$ 


\section{LIST OF APPENDICES}

Appendix I. Letter of Approval

Page 64

Appendix II. Recruitment Poster

Page 65

Appendix III. E-mail to Guardians

Page 66

Appendix IV. Consent Form

Page 67

Appendix V. Assent Form

Page 74

Appendix VI. Layout of Location

Page 77

Appendix VII. Interview Questions

Page 78

Appendix VIII. Thematic Data Analysis of Findings

Page 79

Appendix IX. Child-Friendly Booklet of Project

Page 80 


\section{CHAPTER 1. INTRODUCTION}

\section{Significance and Context of Study}

The World Health Organization has declared mental health a major concern for the world's population. An estimated 20 to 25 percent of children globally were diagnosed with mental health disorders in 2012 (Reiss, 2013). In recent years, researchers have posited that many mental health concerns ${ }^{1}$ have their roots in early childhood, which has led to a focus on understanding mental health in young children (Doughterty et al., 2015).

Equine-assisted therapies and interventions (EAT/I) are increasing in popularity as standalone treatments, or as complimentary treatments that support more traditional interventions associated with mental health concerns. This was found to be especially true for young children, as parents and physicians are more hesitant to administer pharmaceuticals or more aggressive treatments for mental health issues in early childhood (Charach et al., 2013). EAT/I have long been recognized for the ability to support individuals with physical disabilities by improving muscle symmetry, posture, and balance (Smith-Osbourne \& Selby, 2010). Research has now shifted towards exploring EAT/I's psycho-social benefits, such as enhancing self-esteem, socialization opportunities, improved attention span, spatial awareness, verbal skills, selfefficacy, and impulse control (Boyd \& Leroux, 2017; Smith-Osbourne \& Selby, 2010; Srinivasan et al., 2018; Wilkes-Gillan et al., 2015; Wilson et al., 2017).

EAT/I consist of mounted therapies, where an individual rides a horse and performs various tasks to support their treatment goals, and unmounted therapies which include grooming,

${ }^{1}$ The term mental health 'concerns' has intentionally been chosen to disrupt the pathologizing discourse 'illnesses' or 'problems' can have on an individual in our society. This is further explained in the theoretical frameworks section under 'Disability Justice' 
feeding, hand-walking, conversing with a horse, and being in proximity to a horse. While recent research has included a range of approaches from qualitative, quantitative, and mixed methods,much of it has explored the perceptions of adults when treating a child with mental health concerns, rather than allowing the perceptions of children to come forward as well (Anderson, \& Meints, 2016; Boyd \& Leroux, 2018; Wilson, Buultjens, Monfries, \& Larimi, et al., 2017). The growing interest in EAT/I for young children with mental health concerns offers an opportunity to explore a long-used, yet under-researched therapy from the perspectives of the clients—in this case, children — themselves.

\section{The Importance of Interviewing Children}

The concept of 'childhood' as separate from 'adulthood' in western societies emerged sometime between the fifteenth and nineteenth centuries. With this distinction, 'childhood' became understood as a time for protection, dependence, segregation, and deferred responsibilities (Gillespie, 2012). Today, those who find themselves within the confines of 'childhood' exist as a marginalized group, mostly dependent on adults, and often treated as incapable of contributing to society in a meaningful way. The sociology of childhood challenges this conceptualization by advocating that children are not and should not be valued only for their 'becoming' of adults, but as 'beings' in their own right (Dockett \& Perry, 2005; Prout \& James, 1997). Children are competent and capable to participate as active citizens who carry unique views of the world, which must be acknowledged in matters affecting their social worlds.

Around the world, children's perceptions and opinions are a growing consideration when developing policies that impact them, as noted when considering active citizenship (Bartholomaeus, Gregoric \& Krieg, 2016; Wood, 2010). In Australia, youth actively participate in community consultations for services and provisions designed for them, demonstrating their 
ability and desire to participate in local government affairs (Bartholomaeus et al., 2016).

Conversely, in Ontario children are rarely educated on their right to citizen participation, and less often afforded the opportunity to voice their opinions on matters affecting them in meaningful ways.

When it comes to children's healthcare in Ontario, very young children are often denied the opportunity to partake in decision-making, though the decisions directly impact them. Koller (2016) argues that children's opinions should be given due weight in their medical treatment options. In healthcare, children's voices are of particular importance since informed consent in treatment and honest communication between the healthcare provider and patient is a matter of professional ethics and psycho-social well-being of the patient (Koller, 2016). Why then are children's voices often not considered in a meaningful way in their healthcare plans?

By including children's voices in research, there is hope that we will see a shift in children's universal right to express their opinions and perspectives (United Nations, 1991), including expressing their opinions when it comes to their health-related care needs. However, this is easier said than done. Dockett and Perry (2005) acknowledge that the perceptions of children vary from those of adults, and the conceptualization of 'child' and 'childhood' often suppose children and youth too immature and inconsequential to be given due weight. Attaining the knowledge and perspectives that children have of their experiences requires unique datagathering strategies and research designs (Clark, 2007). Researchers must ensure their studies are soliciting the information intended, giving voice to the children involved, and work from a children's rights perspective.

I argue that a qualitative exploration of EAT/I from the perspectives of children with mental health concerns will shed light on the benefits and shortcomings of these therapies, as 
well as give voice to this silenced and marginalized group. My aim is to ensure that the information gathered from children will serve to enhance programming for therapeutic riding farms, offer methods by which children can voice their perspectives regarding treatments, and demonstrate the capability of young children to actively participate in decision-making that will impact their lives and the world around them.

\section{Purpose of the Study}

The present study explored the perspectives of children with mental health concerns on their experiences with EAT/I. The research took place at a therapeutic riding farm in Ontario that is a member of the governing body of Canadian Therapeutic Riding Association (CanTRA). CanTRA has over 80 member farms nation-wide. It ensures that all individuals volunteering or employed at the farms have certification, and all farms and horses meet the sector's required standards (CanTRA, 2018).

The farm at the centre of this study currently has over 150 participants, most of whom are children, and this number increases during the summer months. My project gathered narratives from children on this topic by introducing multiple modes for children to express themselves in the fashion most suited to their preferences (Clark, 2007). Drawing from the sociology of childhood, I explored children's perspectives of their lived experiences, acknowledging children as experts on their own lives, as competent and capable with valuable opinions (Barnikis, 2015; Dockett \& Perry, 2005; Prout \& James, 1997). This study builds on previous research on EAT/I for children by conducting research 'with' children, instead of 'on' or 'to' them. Through their input and insights, I believe that we have a lot to learn.

\section{Positioning myself in the research}


All research contains inherent biases. What we choose to research and how the research is conducted are all decisions researchers make based on their experiences and worldviews. I challenge the notion of a 'neutral researcher' and argue the best way to ensure credibility in research is to explicitly position ourselves in the research. This study is part of the completion requirements for my Master of Arts degree in the Early Childhood Studies program at Ryerson University. When I was given the opportunity to do independent research in partial completion of this degree, I jumped at the opportunity to explore this topic. I have long been a horse back rider, competing internationally in show jumping, and have trained racehorses. I have been an equestrian riding coach in Canada and in Costa Rica and have been involved with therapeutic riding for over 20 years. I recently stepped down from a board of director's position at a therapeutic riding farm after the completion of a three-year term. I have worked with many children locally and internationally and have developed a passion for working with children. I earned a Bachelor of Arts degree from Ryerson University in Early Childhood Studies and have worked with children and youth for over 20 years.

This research is a culmination of two of my passions, horses and children, which are combining to form a third passion, conducting research regarding children's experiences with horses. It is my hope that I will continue this type of research in the future through a $\mathrm{PhD}$ program and in my career. 


\section{CHAPTER 2. LITERATURE REVIEW}

\section{Animal Assisted Therapies}

Animal assisted therapies have been utilized for centuries in hopes to generate a positive impact on an individual's health and well-being (Palley, et al., 2010). One of the earliest documented cases of animal-assisted therapy occurred in the United Kingdom in the 1790s when patients with mental illnesses were treated with walks in the gardens and the assignment of care for small domestic animals (Burch, 1996 as cited in Palley et al., 2010). This type of therapy had grown from the belief that animals provide opportunities for socialization and relaxation, and from the desire to support those who do not experience this — relaxation and socialization — sufficiently in their everyday social worlds (Palley et al., 2010).

Since this time, animal assisted therapies have evolved to encompass assistance with socialization (Anderson \& Meints, 2016), enhancement of physical functioning (Elmac1 \& Cevizci, 2015), emotional and cognitive functioning (Maber-Aleksandrowicz, Avent \& Hassiotis, 2016), and rehabilitation efforts to treat trauma and/or substance abuse (Kelly \& Cozzolino, 2015). Common animal-assisted therapies involve the use of a trained service or emotional support dog, or therapies involving horses. As previously noted, the latter can involve activities based on riding a horse or activities where individuals remain unmounted and engage in various activities from the ground. These therapies are often referred to as equine-assisted therapies and interventions (EAT/I) (Smith \& Selby, 2010).

Equine related treatments come in many forms, from equine assisted psychotherapy (EAP) which is facilitated through a partnership between a licensed therapist and riding instructor, therapeutic horseback riding (THR) where the focus is on physical ability while mounted on a horse, and hippotherapy (HT) which is often facilitated with an occupational 
and/or physio therapist (Wilson et al., 2017). For the purposes of this paper, equine assisted therapies and interventions (EAT/I) will be used as an umbrella term for all horse-related therapeutic treatments.

The purpose of EAT/I is to develop a bond between a horse and a person with a disability, chronic illness, or trauma and use this bond to improve the quality of life for that individual (Boyd \& Leroux, 2017). The beneficial outcomes and skills learned through EAT/I filter into other areas of the individual's life, improving quality of life beyond the barn. Boyd and Leroux (2017) suggest social functioning improves with EAT/I as the horse cannot speak back, is seen as non-judgmental, and improves communications for individuals with autism spectrum disorder.

Alternately, Wilson et al. (2017) suggest individuals may be resistant to speaking to authority figures, so the facilitator can use the horse to develop trust and engage in deeper conversations, which may otherwise be unreachable. When trust is developed between an individual and horse, the horse may be considered non-threatening, and can allow people to open up where they would otherwise be unwilling. Horses offer emotional and physical comfort, can engage individuals in an experiential lesson, and removes the focus from being directly on the individual to the horse, providing a less stigmatizing session.

\section{Equine-Assisted Therapies and Interventions for Physical Disabilities}

Researchers have investigated the benefits and shortcomings of equine-assisted therapies for physical disabilities (Elmac1, \& Cevizci, 2015; Smith-Osbourne \& Selby, 2010; White-Lewis et al., 2017). These are often mounted therapies which involve a riding instructor, an occupational or physical therapist, and a medical professional who come together to develop physical activities for a client to meet goals. These goals often aim to improve balance, posture, muscle symmetry and tone. Physical disabilities that are often treated with THR or HT include, but are 
not limited to cerebral palsy, cystic fibrosis, spinal cord injuries, and multiple sclerosis (WhiteLewis et al., 2017). Empirical evidence in support of equine-assisted therapies in the treatment of physical disabilities is well-documented (Angsupaisal et al., 2015; Fazio, Medica, Cravana \& Ferlazzo, 2013; Giagazoglou et al., 2013; Uchiyama, Ohtani \& Ohta, 2011).

\section{Challenges to Equine-Assisted Therapies and Interventions}

Some research suggests that alternative treatments may only be as beneficial as the passage of time and argue there is not enough empirical evidence to support claims that alternative treatments have benefits to children (Anestis et al., 2014). However, much of this research has failed to investigate alternative treatments as complimentary, and instead have focused on standalone alternatives not used in conjunction with other options. This research has also failed to acknowledge the social development, sense of belonging, and sense of well-being many complimentary treatments provide (Srivinasan, Cavagnino \& Bhat, 2018).

Other researchers argue that there is a lack of empirical evidence supporting EAT/I (Anestis et al., 2014). However, there is strong qualitative support for it and some researchers challenge a lack of empirical evidence by noting that there is a "consistent and reliable positive effect of short-term equine therapies on behavioural skills" (Srinivasan et al., 2018, p. 171).

Qualitative and participatory research into the outcomes of EAT/I for individuals with a disability have investigated perspectives of families, the facilitator(s), the individual with the diagnosis, and teachers, all of whom note positive impacts for themselves and/or the individual (Boyd \& Leroux, 2017; Climie \& Mastoras, 2015; Wilson et al., 2017). A potential reason for the disconnect between quantitative and qualitative data gathered on EAT/I and mental health may be the highly experiential and individual nature of horse-related therapies and varied symptomology and experiences related to mental health concerns, especially in early childhood. 
For example, Dougherty et al. (2015) challenge the suggestion that depression does not often occur in early childhood by acknowledging that symptoms of depression have been considered rare in early childhood due to a lack of developmentally appropriate diagnostic criteria. Poor understanding of mental health concerns is compounded by the heterogenic nature of many of these issues and the lack of a single distinct cause (Te Meerman, Batstra, Grietens \& Frances, 2017).

As mentioned, the lack of developmentally appropriate criteria for very young children is problematic, and the comorbidity commonly found in many mental health concerns adds to the muddying of the comprehension of mental health in early childhood (Dougherty et al., 2015). Furthermore, creating a control group for a subjective experience can be challenging, especially when the perspectives of people connected to the individual are investigated. It is important to understand and respect the perspectives of all involved to gather a better understanding of the potential benefits, or lack of, when engaging in EAT/I. The current study will help create a fuller understanding of this by introducing the perspectives of children.

\section{Mental Health in Early Childhood}

Understanding mental health concerns in early childhood has recently become a topic of interest for various reasons (Poulou, 2015). Mental health concerns can impact an individual's ability to contribute in their role as an active citizen, disadvantaging their mental and physical health, as well as limiting potential upward economic mobility in Canadian society (Reiss, 2013). Unemployment rates in Canada for people with severe mental illnesses are as high as 70 to 90 percent (CAMH, 2019). While economic reasoning has drawn interest to research on mental health, it is important to look beyond fiscal apprehensions. Mental health can include both emotional disorders (such as anxiety, depression, and phobias) and behavioural disorders (such 
as ADHD, oppositional defiant disorder, and conduct disorder) (Poulou, 2015). Included under the umbrella of 'mental health' this paper considers cognitive disorders as the sample were not specifically asked about a formal or potential diagnosis.

Research into the effectiveness of EAT/I for individuals diagnosed with behavioural and emotional disorders have shown both qualitative and quantitative benefits for the individual (Nurenberg et al., 2015; Ewing et al., 2007). Research by Ewing et al. (2007) used a mixedmethods approach to understand the impacts of horse therapy on children with severe emotional disorders. The authors found enhanced conduct and social acceptance among children (Ewing et al., 2007). However, the authors noted disappointment with the little to no change in the domains of empathy and depression, which ran counter to the results they achieved in a previous pilot study (Ewing et al., 2007).

Mental health in childhood is important to understand as it can influence children's subjective well-being. For example, in The Good Child Report, The Children's Society (2018) reported that 47 percent of children who demonstrate high depressive symptoms also demonstrate low life satisfaction. While this is not a causal relationship, a correlation is made clear in the report. Recognizing the influence mental health has on children's well-being is important for developing prevention and intervention strategies and moderating negative outcomes of poor subjective well-being. How children feel about their well-being can be evaluated through objective indicators, such as housing situation, health, and education. It can also be assessed by asking children how they feel about their situation (Bradshaw, Martorano, Natali \& de Neurbourg, 2013). Children's poor subjective well-being and low life satisfaction are linked to truancy, low physical activity, and self-harm (The Children's Society, 2018). 
These issues are detrimental to children and have consequences for the society in which they exist, including suicide, stigma, homelessness, and the economic expenditures required to address these issues (CAMH, 2019). Yet, examining mental health interventions in childhood cannot solely be for the purpose of enhancing their later adult life, but must include how children are being supported within the contexts of their childhoods, as they are living them.

\section{Early Intervention and the Problem with Labels}

With research like that of Dougherty et al. (2015), who demonstrate that psychological problems evident in adulthood often begin in early childhood, awareness is growing of the importance of early interventions. However, concerns regarding assessment, diagnosis, and treatment of preschool children are rampant. Dougherty et al. (2015) conducted a systematic review that shows stability in some psychopathologies from early childhood to adulthood. The authors highlight the need for further data to better understand which behaviours are non-normative, which are transient, and the biological factors that underpin mental health concerns in early childhood. Moreover, the contexts under which a child may exhibit concerning behaviours and the treatments that consider comorbid conditions must be further explored.

The pitfalls which exist in early identification and intervention in the preschool years appear plentiful. This could be due to the lack of training and understanding regarding mental health in this age group, and the lack of reliable and valid measurement tools that are developmentally sensitive and considerate of contexts (Dougherty et al., 2015). Concerns are raised that labelling will stigmatize a child diagnosed with a mental health concern, suggesting that when labels are placed, children can lose their right to be understood as competent learners with valid opinions (Poulou, 2015). This is important to reflect upon as Poulou (2015) notes “developmental psychopathology incorporates a transactional formulation” (p.230). In other 
words, the child is developing within the contexts of their environment, including the relationships they form with the educator and their peers. Considering that labelling a child can alter these relationships, it can be seen how stigmatization can develop and be detrimental to the child's interpersonal relationships. Treatments like EAT/I are non-invasive, engaging and meaningful ways a child can be treated before they receive an official diagnosis that does not stigmatize and is not harmful to development.

\section{The Importance of Alternative Treatments}

In recent decades, pharmaceuticals have become a popular treatment for some mental health concerns. For example, ADHD is often treated with methylphenidate, commonly known as Ritalin (Charach et al., 2013). However, treating mental health concerns solely with pharmaceuticals can be difficult as there is rarely a cure, and symptomology can be highly individual (Dougherty et al., 2015). Additionally, pharmaceuticals used to treat mental health concerns have shown little to no positive long-term behavioural outcomes (Climie \& Mastoras, 2015). Wilkes-Gillan et al. (2015) suggest that when parents are not using the treatments they believe most beneficial for their child, they are 50 percent less likely to engage in the treatments, having potentially negative outcomes for the child. Research into the effectiveness and safety of pharmaceuticals in older youth has been used to suggest the efficacy and safety for use in younger children, however many parents may remain hesitant to administer pharmaceuticals to young children (Charach et al., 2013).

There are many treatments and interventions available for children with mental health concerns. Treatments can be stand-alone, like pharmaceuticals, or complementary which are used in conjunction with medicine and/or other treatments. Treatments, both stand-alone and complementary, for children with mental health concerns can include art therapy (Habib \& Ali, 
2015), music therapy (Srinivasan \& Bhat, 2013), diet (Heilskov Rytter et al., 2015), mindfulness

(Coholic, 2011; van der Oord, Bögels, \& Peijnenburg, 2012), and acupuncture (Moharreri et al., 2018) among others.

Parents and children must be afforded the opportunity to choose the treatments for their children without stigma to ensure ongoing participation and positive outcomes for the children and their families. The desires of the child can (and often should) have a deep impact on how the parents wish to proceed. While medicines like Ritalin can be an effective first-line treatment for children, complimentary treatments, alternative treatments, and parent behaviour training (PBT) may be additional supports for addressing socialization and behavioural concerns (Charach et al., 2013).

\section{Protective Factors in Early Childhood}

As noted above, behaviours can be changing rapidly in early childhood, making assessment difficult (Dougherty et al., 2015; Poulou, 2015). This struggle is magnified as young children are often unable to convey their own mental health problems and reports are often left to the subjective understanding of the adults in the child's life (Poulou, 2015). Challenges to the assessment tools available include lacking contextual understanding. This suggests that ultimately, it is vital that the approach to assess a child is considerate of the unique contexts of the child as this will ensure they receive the most appropriate and individualized intervention. The importance of early identification and intervention of mental health concerns in early childhood cannot be underrated, but it cannot be understood and ameliorated without consideration for the contexts within which the child exists.

Disadvantages in childhood can have lasting implications for mental and physical health. Ferraro, Schafer and Wilkinson (2016) describes how "the accumulation of negative exposures 
raises the risks of subsequent health problems" (p.108). Childhood disadvantage associated with health problems, and the accumulation of negative exposures in childhood has been associated with disease accumulation in adulthood, and the onset of new health problems (Ferraro et al., 2016). Yet, research has shown that protective factors can have intervening effects on health outcomes in later life (Ferraro et al., 2016). Supports for poverty reduction, family provisions, and access to care and varied treatments options are needed to enhance interventions for mental health concerns.

If we can reduce childhood disadvantages by investing in treatment options, these protective factors can be introduced, decreasing inequality gaps, and supporting childhood development. Addressing these protective factors in early childhood can produce preventative strategies for limiting the growth of mental health concerns. Used in conjunction with interventions and treatments like EAT/I, we can begin to better support mental health in young children.

\section{From the Perspective of Adults}

Commonly in research, the adults involved in the children's lives are given the power to speak about or for the child (Boyd \& Leroux, 2017). This is concerning as the therapies and interventions being developed and implemented are for that child, not for the adults.

Boyd and Leroux (2017) investigated parents' perception of EAT/I at a farm in South Africa. They found parents had a unique and positive perspective regarding horse-related interventions with children who had a variety of diagnosed disabilities. These perspectives included positive associations with service provision, a sense that they "were not alone" (p.5), psychological, social, and physical improvements in their children, as well as a calming effect on their children. 
Other research has investigated the perspectives of medical professionals regarding EAT/I with adolescents experiencing depression and/or anxiety. The medical professionals reported improvements in the areas of confidence, self-esteem, and assertiveness. Additionally, the professionals described a heightened ability to reach desired goals through the experiential and non-threatening nature of EAT/I (Wilson et al., 2017).

The subjective experiences and observations of those involved in EAT/I have demonstrated the achievement of predetermined goals. Research in this area must continue to garner a deeper understanding of all perspectives, especially from the clients themselves.

\section{Children as 'Health Actors'}

When it comes to health care, the conceptualization of children as 'health actors' is being explored, with a focus on children in health policy development, children's health and wellbeing, and challenging notions of children's health and normalization (Brady et al., 2015). In research with children conducted by Koller (2016) the issue of children's participation is seen as a matter of ethics and psycho-social well-being. The outdated developmental 'ages and stages' views of children have negatively impacted the conceptualization of children in health care by positing an image of an incapable individual which undermines the child's right to be informed and to have a voice on matters impacting them (Koller, 2016; United Nations, 1991).

A number of studies have shown the importance and value of including children's voices

and perspectives in medical research. For example, research by Linder and Seitz (2017) explored which aspects of hospitalization were most bothersome to pediatric cancer patients. A common concern participants voiced was the lack of sleep due to hospital routines. With this knowledge, changes to hospital routines could be implemented to ensure the patients are able to have a better sleep. The results of this study and others like it can help hospitals, professionals, parents, policy 
developers and others understand the circumstances that affect the lives of pediatric patients and how their experiences can be improved.

Similarly, research by Koller, Khan and Barrett (2015) explored the perspectives of children and youth about diabetic self-care. This study demonstrates the importance of emotional support from parents and professionals in healthcare to mitigate the effects of having type one diabetes. This support enhances the child's ability to partake in self-care, as described by the children and youth. The study by Koller (2016) also demonstrates the competency, agency, and ability the children and youth have in engaging in research, their desire to understand and participate in their medical treatments, and the ability to express their experiences in order to enact change.

Research into how children experience mental health concerns is vital to determining how the health care system responds to needs, and how it may be improved. After all, children have the right to express their views and have their views be given due weight in matters affecting them (United Nations, 1991). While research into children's perspectives may not create a complete picture, it is a vital component to improve health services and experiences in a manner that is meaningful.

Obviously very young children cannot have full decision-making power regarding their care, but a better assessment of their ability to choose to participate based on their "temperament, emotional maturity involving experiential learning and participation in health-related tasks" is needed to determine their willingness and level of comprehension (Koller, 2016, p. 2658). Previous research has demonstrated children's competencies and agency in participating in research, decision-making regarding their health care, and in policy development. Researchers 
must continue to find ways to involve children as they co-construct the social realities in which we live.

\section{Research with Children}

Historically, research has failed to gather the narratives and perspective of children on topics involving them, marginalizing their voices and assuming the perspective of the child (Barnikis, 2015; Dockett \& Perry, 2005). Koller (2016) suggests that developmental researchers tend to omit the voices of children, but if researchers are to assume children's competency from the outset, they will respect the children's agency and rights. This can also have the benefit of alleviating some of the power dynamics that marginalize children in research (Liegghio, Nelson \& Evans, 2010).

While children are considered a marginalized group in research, arguably none are more marginalized than children with disabilities (D’Eloia \& Price, 2018). Dockett and Perry (2005) suggest that research is often done 'on' children and not 'with' them, and unless research acknowledges children's unique experiences, researchers should not presume to speak for them. This remains true for understanding the experiences and results of EAT/I with children who have mental health concerns.

By allowing the narratives of the children to come forward, a better understanding of the child as a whole, with strengths and interests to be supported for future success, can be gathered and fill a gap in the current understanding of children with mental health concerns and the treatment of EAT/I. For these reasons, the proposed research project aims to investigate the subjective experiences of children with mental health concerns regarding EAT/I. This will raise the voices of these children in research and garner a better understanding of the benefits, or lack of, as perceived by the children themselves. It is hoped this research will provide therapists and 
EAT/I program developers important information from the children for the development of future, strengths-based programs for whom they are targeted.

\section{Research Question}

The literature review established the research question for the current study by combining two channels of previous research- one regarding the efficacy of EAT/I, and the other regarding the importance of interventions and preventions in early childhood to address mental health concerns. These channels have demonstrated success in treating mental health concerns with EAT/I for young children as reported by various adults in the children lives but has failed to determine how the children themselves perceive their experiences. Therefore, the main research question guiding this study is: How do young children with mental health concerns perceive their experiences with equine-assisted therapies and interventions? 


\section{CHAPTER 3. THEORETICAL AND CONCEPTUAL FRAMEWORKS}

The importance of a researcher to explicitly position their conceptual and theoretical framework is crucial to understanding the worldviews "through which knowledge is filtered" (Leavy, 2017, p.11). Throughout this research, I worked from a constructivist paradigm which “...emphasizes people's subjective experiences, which are grounded in social-historical contexts." (Leavy, 2017, p.13). It consciously does not seek a universal 'truth'. Instead, through daily interactions, it is believed we are actively engaged in constructing meaning about our reality. A constructivist paradigm is appropriate for this study as it seeks to explore the individual experiences children have with EAT/I. It is important to understand the perspectives young children have of their lived experience within the contexts of each child.

I built my research upon three frameworks: the sociology of childhood, children's rights and disabilities justice. The sociology of childhood framed this research by emphasizing the competencies and capabilities of young children to actively participate in research (Dockett \& Perry, 2005; Prout \& James, 1997) and in the social construction of reality (Leavy, 2017). A child's rights framework guided this study in arguing that children are not only able to voice their opinions but should be heard and given "due weight" in matters affecting them, as specifically stated in Article $12^{2}$ of the United Nation's Convention on the Rights of the Child (UNCRC) (United Nations, 1991, p.6). A disability justice framework is employed to challenge individual, pathologizing and medical notions of 'disability', and to place ability within a more social and

${ }^{2}$ Article 12 of the UNCRC states "1. States Parties shall assure to the child who is capable of forming his or her own views the right to express those views freely in all matters affecting the child, the views of the child being given due weight in accordance with the age and maturity of the child" (United Nations, 1991, p.6) 
cultural context (Harpur, 2012). These frameworks are further detailed below in relation to the topic of children with mental health concerns and their perspectives of their experiences with $\mathrm{EAT} / \mathrm{I}$.

\section{The Sociology of Childhood}

The sociology of childhood sees the 'child' and 'childhood' as social constructs and not as fixed and natural phenomena. This framework challenges the notion that children are worthy of study because they are in the process of 'becoming' adults; opting instead to understand and respect children and childhood as a state of 'being' worthy of study in their own right (Freeman \& Freeman, 1998; Prout \& James, 1997). The sociology of childhood ensures children are present in research, not as objects to have research done 'on' them, or as passive subjects to have research done 'to' them, but as capable active participants in which research can be done 'with' them (Dockett \& Perry, 2005). Children have for too long been a marginalized group in research. Their voices have been omitted or filtered and altered through the perspectives of adults who are asked to speak on their behalf (Barnikis, 2015).

The conceptualization of children as incapable, immature, and dependent has negatively shaped the understanding of children's ability to participate in research and in their health-care. The sociology of childhood will help to deconstruct and disrupt these supposed 'truths' in the dominant discourse and reconstruct the understanding of this age group as competent, active citizens with unique perspectives worthy to participate in matters impacting them. Some of this theorizing and reconceptualization is complimentary to important parallel work being done on children's rights. 


\section{A Child's Rights Perspective}

Past conceptualizations of children and childhood have contributed to a view of children as 'lessthan' or 'not-yet' adults, and therefore not deserving of the same legal rights and responsibilities as adults (Larkin, 2014). Challenging these conceptualizations, I consider children's involvement in matters impacting them as the "best interests" of the child, which is stated in Article $3^{3}$ of the UNCRC, and is also guided by Article $2^{4}$, the child's right to non-discrimination. In Article $23^{5}$, it explicitly states the right to participation for children regardless of mental or physical disability.

The ratification of the UNCRC by every nation in the world, apart from the United States of America, challenges children's lack of rights and has laid out articles for the universal protection and status of children under the age of 18 (United Nations, 1991). Discourse premised on the principles laid out by the UNCRC views young children as agentic and active citizens with unique voices and perspectives. Children are often subject to the decisions and plans of the adults in their lives. However, as previously noted, Article 12 of the UNCRC states that children should have a voice in matters that impact them, and this voice should be used in a meaningful way.

${ }^{3}$ Article 3 of the UNCRC states " 1 . In all actions concerning children, whether undertaken by public or private social welfare institutions, courts of law, administrative authorities or legislative bodies, the best interests of the child shall be a primary consideration" (United Nations, 1991, p.3)

${ }^{4}$ Article 2 of the UNCRC states " 1 . States Parties shall respect and ensure the rights set forth in the present Convention to each child within their jurisdiction without discrimination of any kind, irrespective of the child's or his or her parent's or legal guardians' race, colour, sex, language, religion, political or other opinion, national, ethnic or social origin, property, disability, birth or other status" (United Nations, 1991, p.3)

${ }^{5}$ Article 23 of the UNCRC states " 1 . States Parties recognize that a mentally or physically disabled child should enjoy a full and decent life, in conditions which ensure dignity, promote selfreliance and facilitate the child's active participation in the community" (United Nations, 1991, p.11) 
Research by Sonmez and Ceylan (2017) and de Roiste, et al. (2012) illustrate that participation (Article 23) and involvement lead to enhanced well-being, enhanced perceived academic performance and enjoyment of school, and increased happiness and perceived health. Being involved in and providing opportunities for participation is not only a child's right to be heard and given due weight (Article 12), it is profoundly connected to their right to life, development, and survival, as articulated in Article $6^{6}$ of the UNCRC (United Nations, 1991). Yet, these rights are "more rhetorical than actual and active" (Carter, 2014, p.205).

To ensure children's rights are implemented, action-oriented tools have been developed, such as the Mosaic Approach in research. This approach promotes a multi-modal strategy for children to express themselves (Clark \& Moss, 2001). Strategies in the Mosaic Approach include art, photographs, dramatic play, and the traditional interviews and observations. The Mosaic Approach is a well-established method of allowing a child to express themselves in research in their unique way while engaging in conversation. While it would be more in sync with the Mosaic Approach to engage children in research from the onset, as seen with community-based participatory research, for the purposes of this study and the allotted timeline in which to complete the research, a qualitative study was employed. The Mosaic Approach is used to ensure all children, regardless of ability, can participate. I believe a disability justice framework further entrenches the inclusion of children with disabilities in research.

${ }^{6}$ Article 6 of the UNCRC states " 1 . States Parties recognize that every child has the inherent right to life." And "2. States Parties shall ensure to the maximum extent possible the survival and development of the child." (United Nations, 1991, p.4) 


\section{Disability Justice}

Most research and treatments regarding children with mental health concerns have been focused on remediation of symptoms (Climie \& Mastoras, 2015). This can run the risk of placing a deficit-orientation on the individual child, pathologizing them and perpetuating the statistic that children and youth with disabilities are among the highest stigmatized demographics in the world (D'Eloia \& Price, 2018). The disability discourse debate is still going strong. Some disability activists argue that person-first language, such as 'people with disabilities', pathologizes individuals and forces them to carry the disability while ignoring the societal structures which create these disabilities. These scholars prefer the term 'disabled people', highlighting the awareness that the social structures are the disabling factor on the individual. As Hull (1998) notes:

any definition of disability must take into account the limitations posed by society on disabled people-- for society and the actions, inactions and attitudes of its members are integral to the disadvantages that are bound up with the experience of disability (p.203)

However, as this topic remains highly debated, I opted to use person-first language when discussing people with disabilities. Some disability activists suggest by overemphasizing disability as social and environmental constructs, we run the risk of ignoring "real problems" and define disability in terms of "ambiguity" (Devlieger, 1999, p. 348). Moreover, person-first language provokes the personal experiences of people with disabilities, directing attention to the lived experience (Devlieger, 1999).

People with disabilities are an oppressed demographic in our current contexts and the addition of other oppressions creates deeper complexity. For example, research by Stienstra 
(2015) adopts the theory of intersectionality and a strength-based lens to challenge the dominant discourse of girls with disabilities, recognizing that both girls and the disabled have been historically marginalized in western societies. She argues that by engaging in this research, girls with disabilities can be viewed as integral to girlhood studies. This research is crucial to disabilities studies because it emphasizes that disabilities are not separate from humanity but are a woven part of it. A disability is not something requiring fixing to make the person whole. The person is already whole. It is the neo-liberal conceptualizations of disability that must change. The separation between able-bodied citizens and the disabled must be disrupted.

Furthermore, Climie and Mastoras (2015) argue that research must use a strengths-based lens in order to recognize the many positive attributes in the individual and begin to support the components in their lives which are working. This is especially true for professionals and adults in the children's lives who are not medical professionals. Teachers, social workers, parents, and family members run the risk of stigmatizing a child and potentially creating a learned helplessness if they adhere to a deficit understanding of the child (Climie \& Mastoras, 2015; D'Eloia \& Price, 2018). By adopting a strengths-based lens, adults in the child's life can support and build resiliency where needed and understand areas of strength in order to nurture these strengths and create better opportunities for success.

For these reasons, the present research investigated how children perceive their experiences with EAT/I within the contexts of their lives, and not as an attempt to 'fix' or 'normalize' the child. EAT/I can be understood as activities that aim to include and accept the child as they are with the goal to provide space and opportunities that may otherwise be denied to the pathologized child. 
Discourse is a means by which stigma and discrimination grow. It is difficult to omit pathologizing language entirely in this study since the participants require a medical professional to suspect or diagnose an illness or disability to participate in programming at the farm. However, in an attempt to minimize stigmatization or pathologizing the individuals, I will refer to the children as having 'mental health concerns', and not 'mental illness' or 'cognitive disabilities'. I by no means suggest the children are ill or disabled individually, but they may be disabled by the ways in which society has forced them to be disabled within our historical, physical, social and moral contexts. As Koller (2015) states, "For children with disabilities, achieving meaningful involvement in school and community settings requires overcoming significant social, economic, and political barriers" (p.611). For these reasons, I believe a disability justice framework is integral to my research. 


\section{CHAPTER 4. METHODOLOGY}

My research aimed to explore children's subjective feelings about their experiences with EAT/I for mental health concerns. As a result, I chose a qualitative research study with a constructivist design (Leavy, 2017). Leavy (2017) describes qualitative research as an approach to "robustly investigate and learn about social phenomenon: to unpack the meanings people ascribe to activities.” (p.9). To more fully engage the children in the research project, a community-based participatory research approach would have been beneficial. However, due to time constraints for data collection and completion of the study, a qualitative approach that was limited to semistructured interviews with children was selected.

\section{Power Relationships and Play-Based Methods}

Recognizing that power dynamics between myself (the researcher and adult) and the participants (the children) are present, I introduced strategies to moderate these forces. Safeguarding children's active participation in research (so we may do research 'with' children and not 'on' them) requires an explicit awareness and dismantling of the power relationships present. Prout and James (1990) argue that the social sciences focused on children and childhood help to construct and reconstruct discourses and are not neutral. As Grover (2004) states, "it should be appreciated further that to have some control over how one is portrayed in the world by others is related to issues of human dignity" (p.82). Children, therefore, deserve the right to define themselves through participation in research, instead of leaving adults to create these definitions.

Adding to the power construct in research, researchers set the agendas and parameters of the studies conducted. Adult categorization may be “inconsistent with children's views regarding the appropriate manner in which to analyze and describe their experience" (Grover, 2004, p.90). Also, the data analysis process of qualitative research gives interpretive power to the researcher 
(Grover, 2004). In a study by Lane, Blank and Jones (2019) the authors address the issue of considering children vulnerable in research by noting that power imbalances are present in all research involving human participants.

If we are to consider children as active, capable and competent agents in the world, the same must be true in research. Power dynamics are present in all research, and to address this issue in my research, I used the conceptualization of children as agentic, active and capable. I chose the design based on this conceptualization.

To mitigate power dynamics and ensure the children's voices were at the forefront of this research, I introduced play-based interviewing strategies, remained on the child's level, and used appropriate language. Drawing on the Mosaic Approach to conducting research with children, I chose to provide multiple participatory play-based tools to engage with the children (Clark, 2001). This approach is a multi-modal framework which includes the "traditional methodology of observation and interviewing with the introduction of participatory tools including the use of cameras, tours and mapping... drawing and role-play" (Clark, 2001, p. 334). Koller (2015) found that play-based data-gathering strategies using dolls provided one manner young children could explore complex issues tied to inclusion. This approach also requires us to understand our image of the adult as someone who is actively engaged in the listening and learning process (Clark, 2001).

In addition to the play-based tools for participation, Lane et al. (2019) communicate the importance of the environmental context and rapport between researcher and participant. To address these concerns, I set up the interviews in a private location familiar to the children, and the interviews were conducted on the child's physical level while engaging in play with, or 
alongside them. Semi-structured qualitative interviews were used with open-ended questions to allow for important data outside the parameters of the interview questions to come forward.

\section{Qualitative Interviews with Children}

Qualitative data has a richness and depth not often available in quantitative data. For example, in a mixed-methods study conducted by Donnell and Rinkoff (2015), the authors looked at how culture influenced children's perceptions of nature. By examining photographs of nature with children from Canada and Slovakia, drawing and engaging in conversations, the authors could explore how children felt about and experienced nature. The quantitative data demonstrated that nearly 25 percent of children interviewed in Canada and in Slovakia placed water in their drawings. However, by listening to the qualitative data we can understand why water is important to them personally. For example, a Slovakian child explains their drawing by stating "this is a nice beach where you can rest, swim and you can relax. Simply, it is a pleasant place where you have at least a moment of peace.” (p. 75). The qualitative data produces an understanding not attained with the quantitative data alone.

The use of qualitative interviews with children is supported as well by a study conducted by Raby, Lehmann, Easterbrook and Helleiner (2018), which investigated the contexts under which young people engaged in their first jobs. The qualitative data generated from these interviews placed the experiences of the youth at the foreground, deepening our understanding of the reproduction of "dominant, often contradictory, beliefs and practices relating to young people and paid work in the Global North..." (p.248). By allowing the voices of the youth to come forward in the study, a better understanding of the motivations and contexts of beginning work (familial supports, desiring an income, strategizing for the future) can be grasped. 


\section{Participants and Recruitment}

To understand the phenomena of children's experiences with EAT/I, it is important to gather evidence from multiple perspectives on a wide range of related topics. The perspectives of parents and professionals have been well documented and are recognized as vital parts of understanding the health and well-being of children with mental health concerns (Manning, Hemingway \& Redsell, 2017). However, gathering the perspectives of children who experience these concerns and EAT/I will create a better understanding of this phenomena. I argue that by inviting and exploring the perspectives of children we will develop even better policies and programming at therapeutic riding farms and beyond. I argue that choosing a sample made up only of children was key, so that they are not drowned out by the voices of professionals, parents and other adults.

The participants were five children aged five to twelve years old who have mental health concerns and have participated in at least one session of EAT/I. The participants attended a notfor-profit therapeutic riding program located in Ontario. The farm is an accredited member in good standing with the Canadian Therapeutic Riding Association (CanTRA).

While it was impossible to eliminate all risk from this project, it was determined that the benefits outweighed the risks. There was a risk of the participants' identities being revealed. To mitigate this risk, I referred to each child with a pseudonym, their age, and make note of their gender. Confidentiality and privacy were paramount throughout the project and after. The participants and their guardians were reminded that there was no intended outcome, and the narratives of the children guided the process of data collection.

This project advances knowledge in various research areas, including the importance of incorporating a social justice perspective in research, doing child rights-based research, and 
research using the sociology of childhood for richer policy development. By introducing the perspectives of children, policy makers are better able to create policies and programs that are informed with this marginalized group. The project has a lasting benefit to the farm by presenting a booklet exploring the project, opening future conversations that are child-led and child-centered.

To gain access to participants for this study, I first had to obtain permission from the university's Ethics Board (REB) to proceed. After receiving approval from the REB, I approached the board of directors of the therapeutic riding farm and presented my proposal. With a letter of approval from the board of directors (See Appendix I), I was allowed to post a recruitment flyer (See Appendix II) in the barn on the notice/events board that is regularly checked by families, volunteers, and staff.

As a former member of the board of directors, I decided a recruitment flyer was appropriate to give the families power over initiating contact. While I was unknown personally to the families and children, some may have recognized my name. I ensured that prior to each interview I was explicit about stating that I had been on the board but had recently stepped down and no longer held any position or decision-making power at the farm.

The recruitment flyer asked any interested parent(s)/guardian(s) to reach out via e-mail if they and their child were interested in participating. Once e-mail contact was made (See Appendix III), consent and assent forms were e-mailed for the families to review in private (See Appendix IV \& V). If the family agreed to move forward a date and time was set up for the interview.

I intentionally limited the sample size to five children so I may have the ability to delve deep into the narrative of the small number of participants, before reaching saturation (Leavy, 
2017). I chose a relatively young sample (age five to twelve) as the sociology of childhood has in recent years focused on youth and failed to incorporate the voices of the very young (Albanese, 2009). I believe it is crucial to involve young children in research and policy development, and to acknowledge their capabilities to participate. I recognize that the sample age range- -five to twelve - includes a wide range of skills and capabilities, and that a narrower range may have allowed me to probe more profoundly. The programming at the farm included children between the ages of four and twelve and I did not want to exclude any of the children who may have wanted to participate. Recruitment was open to children aged four to twelve, however no children aged four chose to participate. Moreover, the nature of mental health concerns could mean that children of varying ages may have similar capabilities.

Due to the number of gatekeepers involved when conducting research with children, and the programming at the farm, I felt that convenience sampling would allow me the best chance of access (Leavy, 2017). As I grew closer to the project, I found that purposeful sampling gave me access to cases that had previous knowledge and experiences with EAT/I.

\section{Consent and Assent}

After obtaining written support from the therapeutic riding farm, family consent forms and assent forms were distributed to the guardians via e-mail. This allowed the forms to be reviewed preceding agreement to an in-person meeting. Prior to the interview, consent was reviewed with the guardians and signed by them, then assent was reviewed with the participant and signed by the children. All participants who signed the forms completed the interview process. After written consent and assent had been gathered, I ensured the guardians and participants were aware they could withdraw their consent and/or assent at any time throughout the study. 
The data collection consisted of semi-structured interviews which allowed an investigation into both the feelings about and experiences the children have, while ensuring the children could guide the conversation, elevating the knowledge they wish to share. Leavy (2017) describes interviews as a method which uses "conversation as a learning tool." (p.139), as people are naturally conversational.

\section{Interview Process}

In the farmhouse, I created a comfortable sitting area where the individual participants could sit, stand, or move around as they wished (See Appendix VI). I used field notes to quickly mark any important thoughts or information that may not be heard on the audio-recording, and to ensure reflexivity was used throughout the research (Leavy, 2017). Drawing materials such as paper, crayons, markers, and pencil crayons were present, so the children had the opportunity to draw. Drawing is a safe and familiar activity for most children and has been used in previous research to engage children in conversation (Barnikis, 2015; Donnell \& Rinkoff, 2015). This was done by asking them to draw the farm or a horse, if they so chose. This allowed a conversation to develop naturally between the child and myself, which was then used to embed specific questions. Since the drawings were used as a means to build rapport, and not for data analysis, the drawings were not collected and remained the property of the children. I asked permission to photograph the children's work to create a child friendly booklet about the project upon completion. I participated in drawing as well to create a sense of comradery. If the child did not wish to draw, they could play with the toys present such as a toy farm or stick horses, or they could engage in conversation with no other mode of self-expression.

Multiple modes of self-expression available to the children allows for various data collection techniques and focuses on the strengths of the participants (Clark, 2011). However, 
care was taken to ensure the researcher was not interpreting the child's work, but that the child's intentions were brought forth. This was achieved by posing clarifying questions to the child and repeating their statements to ensure the correct information was being understood.

Each one-on-one interview took approximately thirty minutes, depending on how long the child wished to engage in conversation. A break was offered at the mid-point of each interview, or upon request. The interviews were audio-recorded to gather the exact words of the children (Denscombe, 2010; Leavy, 2017). Specific open-ended questions were developed to guide the conversations (See Appendix VI), but the interviews were adaptable based on what each individual child wanted to explore.

\section{Data Analysis and Interpretation}

I employed elements of Grounded Theory in my analysis to ensure the voices of the children are at the forefront of the study. Grounded Theory involves an immersion into the data to inductively discover theories and suggest future research. This allowed me to look 'at' the data, and not 'for' data, elevating the voices of the children (Robretch, 1995). Having been developed by Glaser and Strauss in 1967, Grounded Theory has since evolved and no one 'correct' approach exists (Coholic, 2011). Once data collection was complete, the interviews were transcribed verbatim to immerse myself in the child's voice, noting where the child placed emphases (Leavy, 2017). Denscombe (2010) notes this strategy allows the data analysis to "stay true to the original" (p.95). The transcripts were coded to identify themes based on the research question.

The children's responses were coded and placed into emerging categories (See Appendix VII) for better interpretation based on patterns (Leavy, 2017). Throughout the research study, each child was given a pseudonym to ensure confidentiality (Leavy, 2017). Additionally, the horses, staff, volunteers, or other adults in the child's life that the child referred to were given 
pseudonyms to ensure confidentiality of the farm and those associated with the farm. The names and corresponding pseudonyms were kept separate in a locked filing cabinet, in a locked office accessible only by the researcher. After the period of one year of completion of the project, the name-pseudonym document will be destroyed, along with the consent and assent forms. Any identifiable information kept on a computer is encrypted and password protected for confidentiality (Leavy, 2017). The university's Google Drive was used for all information pertaining to this study, with the exceptions of consent and assent forms and the namepseudonym document, which were filled out on paper copies.

\section{Coding and Themes}

Using elements of Grounded Theory, data were collected, and categories and analytic codes were developed. Open coding was developed by reading the transcripts multiple times to acknowledge repetition and themes (Noble \& Mitchell, 2016). The emerging themes were clustered and working definitions were given to each cluster. For example, emotions were clustered into 'like', 'dislike', and 'neutral' feelings to determine what was liked and not liked by the participants. Previous research by Kalvaitis and Monhardt (2012) and Bixler and Floyd (1997) investigated children's feelings, focusing on the words chosen to express positive emotions associated with certain topics. Words like "happy" and "fun" were considered to express positive feelings, whereas "scared" and "icky" were associated with negative feelings. However, there was some overlap between clusters. For example, one child thought the smell of horses and the farm was a negative, while another spoke of it in a positive manner. The data were placed into major themes that emerged, supported by secondary themes that were determined by tertiary themes. 


\section{Dissemination}

Upon completion of data collection, a research paper will be submitted to the Master of Arts in Early Childhood Studies at Ryerson University to examine and for possible publication and conference presentations. The information was placed into a child-friendly booklet for the farm to maintain (See Appendix VIII). This allows an opportunity to debrief the children and their guardians on their participation in the study and offers and opportunity for the children to reflect on their experiences throughout the project. The final paper will be used for conference presentations and $\mathrm{PhD}$ applications. 


\section{CHAPTER 5. FINDINGS AND ANALYSIS}

Using select aspects of Grounded Theory for analysis, three overarching themes emerged and were divided into secondary, and tertiary themes. The three overarching themes were: 1 . Experiences with the Horse(s) (direct experiences); 2. Experiences with the Farm (indirect experiences); and 3. How the children's experiences on the farm connected to other aspects of their lives (See Appendix VII). The latter was important to address as a major theme as the information was not explicitly solicited, yet all the children made connections to other lived experiences.

\section{The Participants}

Alex (girl) was five years old at the time of data collection, both Taylor (boy) and Robin (girl) were eight, Jordan (boy) was nine, and Jamie (boy) was twelve. The farm did not provide programming over the winter but at the time of the interviews had started the spring sessions. All the children were attending elementary school and had their lessons on evenings and/or weekends. At the time of the interviews, the children were engaged in both mounted and unmounted activities at the farm. All the participants were enrolled in EAT/I programs because they were experiencing mental health concerns. Children who were experiencing both physical and mental health concerns were invited to participate, however as the study examined EAT/I and mental health concerns in young children, data were only collected for those children exclusively experiencing mental health concerns.

\section{Children's Experiences with the Horses}

My interviews revealed some interesting insights into the children's direct experiences with the horses. I listened closely to the children describing their direct interactions with the horse(s). I listened for the nouns and pro-nouns children used to relate to the horses at the farm, such as 
“when I'm with [horse's name]”, or “(S)he makes me feel...”. Other identifiers that I paid attention to related to the riding experience (actions and activities), such as the children's explanations of what they and the horse do together, for example, "[Horse's name] and I do...", or "I like to do...".

All the child first spoke of their direct experiences with the horses before exploring their indirect experiences with other aspects of their time at the farm. The reports about their direct experiences with the horses broke down into four sub-themes, which included their physical interaction with the horse, their emotional connection to the horse, social aspects of their interaction with the horse, and their reflections on what they would change at the farm so that they would have an even better experience with the horse.

\section{Physical Interactions with the Horses}

Throughout the interviews, the children spoke of their direct physical experiences with the horses. Interestingly, their description of their physical connection with the horse appeared to fall into one of three themes, which included their tactile, visual, and movement experiences.

Visual experiences were related to how the children experienced viewing the animals. For example, when I asked why Alex liked the horses, she spoke of enjoyment of the horses in a visual manner. She openly shared that she liked the horses because "ummm...cuz [because] dey [they] pwetty [pretty]... all of dem [them]. Yeah, I tink [think] dem [them] all pwetty [pretty]"' Here, Alex makes evident her enjoyment of the beauty of the horses in a visual capacity.

${ }^{7}$ To clarify Alex's language, I repeated her answers to her, to which she would correct me or agree to what I had repeated. I tried to keep all the children's quotations as close to the originals as possible, however, due to certain identifiable traits, some of the quotes had to be altered. This was done without losing the message of the quotation. 
Similarly, Robin spoke of her horse as being "so cute", echoing Alex's visual pleasure of looking at the horses.

Tactile experiences were related to how the children felt when they touched the horses. Three of the children spoke of the 'warmth' and 'softness' of the horses in a positive manner. Alex noted that she 'like dey [they] soft and dey [they] warm. Dey [they] feel nice.” Alex's sentiments regarding the visual and tactile experiences resonated in the interview with Robin, who, when asked what she likes to do with the horses, stated "I like rubbing her...like a massage." Here, Robin is noting the enjoyment of physically rubbing the horse, and the soothing sensation of touching her horse while rubbing it. Jamie spoke of the softness of the horses' fur as well.

Not surprising, many comments made by the children regarding the physical aspects of the direct experiences with the horses related to movement. These included comments about what the child did while mounted, or they described the unmounted activities that spoke to the action of the experience. Jamie spoke of the activities in which he participated during lessons including, "I can high-five people, or put rings on poles, but you gotta do it while walking [mounted] so it's hard. You're not like standing still." Jamie spoke in a neutral tone about the physical activities he had to do during a lesson, neither positive nor negative, just as a matter of fact. Taylor spoke of similar mounted activities but noted that these experiences helped him "move better."

Common mounted activities at the farm include strategies to stretch, strengthen, and improve the children's balance. The individuals are asked to tighten up on the reigns, forcing them to move their bodies forward and closer to the horse's mouth. Or, they may be asked to lean back until their heads are resting on the hind quarters of the horse. They can stand up in their 
stirrups forcing their heels down, stretching their calf muscles and engaging their thigh muscles. Activities performed at various speeds (walk, trot, canter), can improve balance and muscle tone further. Often, instructors use props to make these activities fun and playful, such as hula-hoops that must be passed back and forth between hands over the neck of the horse. Most of these activities help with an individual's movement.

All the children seemed to enjoy the direct physical experiences they encountered with the horses, even if they noted that what they did was "hard", or that the horses were "smelly." When doing this, the children clarified that they liked the hard tasks because they felt challenged and competent, or even enjoyed the smells of the horses.

\section{Emotional Connections to the Horses}

All five children reported on important emotional experiences that they had with their horses. These emotional experiences were easily classified into three sub-themes: 1 . the enjoyment of being with the horses; 2 . how the horses made them feel; and 3. the child's development of selfconcept through their direct experiences with the horses. Each of these will be discussed in more detail below; however, there was no doubt that a key part of what the children shared reflected their enjoyment of being with the horses. I could not help but note the children's use of words including: 'like', 'happy', 'good', 'smile' and 'love' when speaking about their experiences with the horses (more below). The children were very reflexive and did not fail to use phrases such as 'I'm calmer', and 'they [the horses] like you.'. It was especially striking how large and important the theme of the development of self-concept was in each conversation with each child. This important topic included them talking about competency and self-efficacy, self-esteem, and persistence. Let us explore some of these in more detail. 
Each child began by speaking about their enjoyment of being with the horses. In one interview, Robin was speaking about being happy. At which point I probed: "What makes you feel happy?" To this she responded, "I smile a lot when I'm here...I think everyone in the world would be happy if they got a horse." Robin continued to convey her appreciation of horses and how she felt being near them. She then thoughtfully reflected upon and proceeded to decide which horse would match well with each of her family members to make them happy.

Jordan also compared his experiences with his family and friends to his experience with the horses. Through that comparison, he explained that he liked horses because "It's easier to be with them" When I asked him to clarify this comment, he explained “They [horses] don't care. They like, they like you no matter what [laughs], so long as you have apples." This comment sheds light on some of Jordan's more strained relationships outside of the farm (which will be discussed in more detail in the section 'Connecting to other lived experiences'). Jordan was not alone in this. The unconditional acceptance the horses have of the children seems to play a major role in the children's emotional enjoyment.

Three of the children directly spoke of how the horses made them feel. Robin explained why she felt happy at the farm by saying "The horses just make you happy. It just feels good." Robin later declared that she likes the horse named "Skittles" (pseudonym) the best because "She's super cute. She loves me." Robin seems to enjoy not only how she feels about Skittles, but also, and possibly more importantly, how she perceives Skittles feels about her.

Taylor made a similar comment when I asked him what it was about his horse that made her nice. Taylor replied: "she likes me. She lets me brush her and get on" Like Robin, Taylor was happy about the notion that the horse likes him, and the horse demonstrates this by allowing Taylor to do certain activities. 
Interestingly, Jordan noted that he got "calmer" when he was with the horses, either mounted or unmounted. Jordan explained that the proximity of the horse and the requirement to be alert to their body language had a calming effect on him, of hav[ing] to focus on [the horse]. If you don't, you might get kicked. Like when you pick feet, with a hoof-pick, you gotta clean their feet, right? You gotta pay attention, cuz if there's like a fly on them, they might kick at it and get you instead.

Jordan seemed to connect the focused attention and length of time focusing his attention on the horse as a calming mechanism. He also noted a calming effect when petting the horses. He said they "just feel good, so that makes me feel good. And I, like, I like to feel that, I can stand still and do that forever." The direct physical tactile experience Jordan has with the horse created what he recognized to be an increase in his attention span and a calming effect on him, which are often the stated goals of EAT/I for mental health concerns.

A dominant theme that emerged during the interviews was self-concept. Three of the five children referred to their competence and self-efficacy, self-esteem, and persistence. What was most surprising during these interviews was the children's intentional and explicit commenting on these themes. I was especially struck by the quite regular occurrence of asking a child a question about one thing but them switching the topic, to speaking about their self-concept and self-confidence. When I asked about their drawings or play, they often spoke directly about a moment of pride.

In equine-assisted therapies and interventions, individuals are afforded the opportunity to care for horses, and to ask those horses to care for them by participating in intentional 
programming to improve physical aspects and also aspects of their self-concept. The children in this study clearly have demonstrated positive self-concept. Jordan, for example, showed pride of his ability to "get up on" the horse without the use of the ramp, and of his ability to do "aroundthe-worlds", an activity where the horse stands still and the rider moves their bodies so they first sit side-saddle, then facing backwards, then the opposite side-saddle, and finally sitting forwards. Jordan explained that he's "like really good at it now, I can go fast, like super fast. I didn't want to at first, cuz it's like scary, but now I can go fast."

When I responded to this statement by saying "You sound really proud of that", he confirmed by adding, "Yeah, not everyone can do it." By acknowledging that he was fearful to complete this task at first, but can do it "super fast" now, his competence has led to pride, enhancing his self-esteem and bolstering his self-confidence.

During the interview with Jamie, he spoke of his favourite horse Stewie and how he has developed a strong bond with him. When we explored this bond deeper, Jamie began to note moments of power and control, and of Stewie's response to Jamie's requests. One exchange with Jamie went as follows:

Interviewer: Oh yeah? Why do think he's [Stewie] so cool?

Jamie: Cuz. Cuz he's really big. And he's easy.

Interviewer: Easy? What do you mean?

Jamie: I guess he's nice. He's never bad.

Interviewer: He behaves for you?

Jamie: Yeah, yeah he behaves. When I kick him, he goes faster, or when I pull up, he stops. 
Jamie seems to enjoy Stewie because Stewie offers Jamie the opportunity to lead him and guide their actions. Jamie liked the fact that Stewie would listen to him, even though Stewie is much larger than Jamie and could easily disobey.

In the conversation with Robin, the same notion of power and leadership was made evident when Robin described why she likes her horse so much. She said: "Cuz she's like my henchman [laughs]. Like I'm the boss and she's like my henchman." Robin is describing a clear power dynamic where she can lead, and her horse will follow. This opportunity for power has imparted a sense of pride in Robin who seems to enjoy taking responsibility for the horse.

While the children spoke of leadership opportunities at the farm, and of power and control, it was interesting to note how they often compared these opportunities at the farm with opportunities (or lack of opportunities) in their formal school settings.

\section{Social Interactions with the Horses}

The social interactions the children have with the horses were spoken of in a positive manner. The subthemes that emerged from the children's discussion of social interactions with the horses included friendship, acceptance, and empathy.

The theme of friendship emerged often when speaking about what the children liked about the horses. When the children spoke about their direct experiences with the horses, it was rarely without mention of their emotional bond with the horses. For example, Jordan spoke of his bond with Buttercup (pseudonym), stating that he felt "really good" with him and that he's "my bestest best friend". When asked to explain why Buttercup was his best friend, Jordan was unsure how to answer.

In contrast, Robin was able to articulate and explain her friendships with the horses noting "they're just as special as people." Robin appeared to be accepting the horses' way of 
being, as friendship, in the same manner as humans. Taylor's comments relating to friendship are exemplified through the acceptance he feels from Skittles and the trust he has in her. This is evidenced through the following interaction:

Taylor: ummm, yeah. I talk to Skittles.

Interviewer: Wait... you don't talk to anyone else? Ever? You're talking to me right now. What makes Skittles special to talk to?

Taylor: Ummm. She listens. I can tell her things I don't tell anyone else.

Interviewer: Things like what?

Taylor: I don't want to say.

Interviewer: That's ok. You don't have to tell me anything you don't want to, right?

Taylor: Yeah.

Interviewer: So why do you like telling Skittles things you don't tell anyone else?

Taylor: Cuz she listens, and she won't tell anyone

Taylor is able to express his feelings of friendship with Skittles by noticing Skittle's ability to listen in a non-judgemental way and be trusted with Taylor's deeply held secrets. This friendship appeared very important to Taylor as someone Taylor could confide in, and without whom he would not be able to share his secrets.

Another social subtheme that emerged from the children's experiences with the horses was the notion and experience of empathy that the children felt for and from the horses. The children often spoke of the things horses enjoyed. They spoke of foods the horses liked, what actions, like brushing and rubbing, the horses enjoyed, which had them thinking from and about the point of view of others (empathy). An example of this was when Jamie showed empathy for 
the horses and the one donkey that is onsite at the farm. He did this by noting the differences between the horses and donkey and identifying their differing needs. On this Jamie said, “...they [the horses] just want carrots and mints [laughs]; except Carmen. He's the donkey. He doesn't care. He won't come when I call him, even if I have food." Jamie is able to understand the different personalities and characteristics of the animals and recognize the differences in their corresponding wants and needs. He can understand the feelings of the horses and the donkey separately and individually. This is an important skill and profound outcome of Jamie's interactions with animals on the farm.

\section{What They Would Change}

Each child was asked what they would change about the farm if they could, or what they liked the least about the farm. Most of the responses were directly associated with the horses, but were also things that the children recognized were things that were not easily changed. For example, as Robin put it: "you just gotta get used to it" One of the things the children liked the least about the farm was the smell of the horses, although Robin notes that her horse "smells good, I like that smell." However, later Robin told a story of her stepping in horse droppings, which was "gross". Only Alex noted a negative aspect about being mounted on a horse, that riding was sometimes "bumpy" and that this resulted in her feeling "sore" afterwards.

For the most part, the children enjoyed the direct experiences with the horses. The children had to be explicitly asked to think of the things they did not like, or that they liked the least, to solicit this information.

\section{Children's Experiences with the Farm (their "Indirect Experiences")}

The children spoke about their experiences at the farm that were not about the relationships with the horses. These experiences include interactions with staff, volunteers, and other clients at the 
farm, or with physical spaces at the farm. When I began identifying these, I found that they fell into secondary themes about the physical spaces the children experienced and social and emotional aspects of the farm.

\section{Physical Spaces at the Farm}

The children reflected thoughtfully on the physical spaces that made up the farm and that shaped their farm experiences. Jordan was eager to speak about his time riding outside and was disappointed with the recent rain that prevented this. He refers to being outside as "the funnest part", and "can't wait until we can ride outside in the outside [ring]." The farm hosts both an indoor arena and a riding ring outside where lessons can also be provided. Jordan made clear his enjoyment of being with horses, and this enjoyment appears to amplify if they can be outdoors as well. This demonstrates that EAT/I are not only about experiences with the horses, but with the space in which the farm exists.

Alex also spoke about the jungle gym at the farm, which has special equipment for children of all abilities. She was speaking of wanting more time to play on the jungle gym because she enjoyed it so much, “...like I play der [there] when deres [there is] time, but der [there is] never no time." Alex is explaining that while the horses are the focus of her therapy, the jungle gym is a place of enjoyment as well and should be allotted time during her lessons at the farm.

\section{Social and Emotional Experiences at the Farm}

The children spoke lovingly of the interpersonal relationships they have developed since starting at the farm. These relationships were with staff, volunteers, and other individuals participating in the programming. While the children may not have been aware of the distinction, the volunteers 
are different from the staff, and are the people who walk alongside or guide the horse from the ground during lessons.

The children felt they had good relationships with the staff and volunteers and spoke of how they felt supported by them. Alex explored her relationship with Jo, an instructor, who she felt was "nice... she be nice wit [with] me. Help me do tings [things] to get weady [ready]..." I further explored this with Alex by asking her if Jo was "helpful? She makes sure you can do the things you want to do?" to which Alex affirmed "ya." Alex spoke positively of her relationship with Jo as someone who was kind and willing to help Alex participate in the lessons. Only Taylor had one seemingly negative comment to say about the staff and volunteers when he explained that "sometimes they rush me because I like, sometimes I take too long, but mostly they're nice." Arguably this is not a comment about the staff and volunteers, but of the temporal environment often seen at many horse farms where lessons are given on a fixed and full schedule.

The relationships the children have with other riders played an important role in the development of prosocial skills on the farm. I found it especially interesting that the children were able and eager to identify the benefits that the farm had for others- - their peers or generally other people who might benefit from riding and the farm. For example, Jordan spoke of the benefit of making riding accessible to anyone when he described the special equipment in the following interaction:

Interviewer: What's that? (pointing to Jordan's drawing)

Jordan: That's the saddle.

Interviewer: Oh, good, you need that to stay on, right?

Jordan: Yeah, but some saddles are special. They like have stuff and... are meant for people who need help sitting up. 
Interviewer: Really? That sounds super cool.

Jordan: Yeah, everyone gets to ride if they want. Doesn't matter if they can't do other things. Interviewer: Other things like what?

Jordan: Umm. I dunno. Like some, like some people can’t walk or like have trouble with it. Interviewer: Oh, so they get to ride the horses even if they can't walk?

Jordan: Yeah, it's cool. Like, if you're on a horse, no one knows if you can walk or not. So long as you have the right saddle. It like doesn't matter to anyone, and the horses don't care. They just like walking and getting ridden and [trails off]"

Through this profound insight, Jordan shows empathy and an appreciation of the farm to help those with physical disabilities. When he notes that "It like doesn't matter to anyone, and the horses don't care," he is demonstrating the acceptance of all abilities at the farm. This feeling of acceptance is echoed by Alex who, when speaking of the thoughtfully-designed, accessible jungle gym, states “It's fun. It's for everyone...it's special." Alex is commenting on the fact that the jungle gym is designed for people who use mobility equipment such as wheelchairs and walkers.

Along the same lines, in the interview with Robin made a statement about acceptance at the farm that struck me while we were speaking of accessibility outside of the farm. On this Robin said, "here, it doesn't matter what you can do... And like, some kids get made fun of, but here they don't. They're not supposed to, but they do. Not here though." Robin's statement highlighted for me the important fact that the children consider the farm as a 'safe space' not only in terms of accessibility, but acceptance for the variance in personalities and abilities. 
Taylor also appreciates the impact the farm has for others when he said that the farm, "is a really special place. It helps a lot of people...like helps them walk better and gives them friends" Taylor showed a deep gratitude for how the farm impacts others, not just himself.

Among the five, only Robin spoke about her self-concept in terms of her experiences and relationship to the physical space at the farm. She spoke about what the farm has taught her, "it's just a lot of fun. I like that I can help other people because I have more experience.” Robin is referring to her knowledge of where equipment is located at the farm, how to tack-up the horses, and how to groom the horses. This demonstrates Robin's pride and positive self-esteem when it came to her ability to take a leadership role, help others, and navigating the physical space.

\section{What They Would Change}

The things about the overall farm experiences that the children would change were generally touched upon above, including Jordan's desire for more time spent riding outside, and Alex's wish to have more time to play on the jungle gym. Interestingly, in both cases, the changes were that they wanted to do more and spend more time at the farm-something that indirectly underscores the positive experiences that they have while there.

In addition to these suggestions, Taylor noted that his special relationship with Skittles, to whom he could share secrets, was hampered by there always being another person present. When asked why he had to whisper to tell Skittles secrets, he said "cuz there's always someone there...it gets busy. People are always around." Taylor goes on to declare that he wishes for more private time with Skittles. Alternatively, Jamie spoke of missing his friends when he was at the farm. While many enjoy the safe space the farm offers, Jamie felt his time at the farm would improve if his friends were able to attend as well. 


\section{Connecting to Other Lived Experiences}

The theme of the children connecting their experiences at the farm to other lived experiences outside of the farm was a striking finding. The connections that the children made to other parts of their lives included connections to school, and to accessibility (or lack of) in their homes and communities.

\section{Connecting to School Experiences}

Three of the children compared their experiences at the farm to their experiences in their school settings. For example, while speaking of his experiences at the farm and his desire for including his non-farm friends, Jamie noted “...my friends would like it here. And they're cool. They wouldn't be mean or anything to anyone." In response to this I asked, "Do you have any mean people in your life?” After a brief pause, Jamie replied:

Well, like sometimes. Like sometimes I have to turn my desk to the wall in class, so kids make fun of me for that, or think I'm weird. But it's not bad. We're not supposed to bully people. Bullying is wrong, but like sometimes it happens anyways. I just ignore it.

I was disturbed by the revelation that Jamie is disciplined in his school by physically isolating him from the opportunities that would help him explore and develop his social skills. At the farm, staff and volunteers are trained to help children integrate and develop social skills in a safe and non-judgemental manner. In contrast, at his school, it appears that Jamie's teacher is denying him the very interactions with others that he seems to crave and need. It also seems to further stigmatize him and contribute to isolation and bullying by his peers. 
Jordan similarly spoke about his experiences at school in a negative light when compared to his time at the farm. This was exemplified in the following interaction:

Interviewer: Who tells you to slow down?

Jordan: Everyone! And I don't want to sometimes. Like, I want to do something, but they won't let me. It's so stupid. Like, if I want to just play Pokemon. People are stupid sometimes. Interviewer: Who stops you from playing Pokemon?

Jordan: Well, my teacher, like when I'm supposed to be doing work. So, I can't do what I want. I finish my work fast, but I still don't get to play.

Interviewer: That must be frustrating. What about at [the farm]? Do you get to play Pokemon when you're here?

Jordan: Not really. But like I don't usually want to play Pokemon when I'm here. I like don't have time. I'm either getting ready, or riding...well, sometimes when I'm waiting for my mom to go home, I'll play.

Jordan, who is a very energetic child, seems to clash with the standard school setting of having to sit at a desk for extended periods of time, and focusing on one activity at a time. $\mathrm{He}$ enjoys having the time and space for physical activity and being allowed to focus his attention on various things. At the same time, he seems to have no trouble focusing on riding and admits that the thing that he is rushing to do at school—play Pokemon—isn't much of a consideration when he is engaging in things that he enjoys at the farm.

During the interview with Robin, the theme of leadership opportunities at school came up. Robin was speaking of her love of riding and being 'the boss' and her horse being her 'henchman'. She also noted that she would "like to ride to school, like not in the bus, on 
Buttercup, and I would get to ride and be in charge and no one else could...like then my teacher would let me do stuff cuz she could see I could like ride, so I can do other stuff too." I asked what her teacher didn't let her do, to which she stated, “like she doesn't like, I never get to be in charge. Mrs. Snow lets me do stuff on my own, but like only when I'm with her. But Mrs. Blue doesn't let me be in charge. She always picks someone else.” By being in charge of Buttercup during a lesson, Robin is able to take advantage of the leadership opportunities she clearly enjoys.

\section{Connecting to Community Experiences}

During the interview with Robin, we spoke of the feeling of safety at the farm, because everyone was nice to each other. This conversation was prefaced by a discussion of when the farm was closed for a long period of time:

Interviewer: Is there anything else you want to mention about [the farm]?

Robin: I think it's really nice that it's here. I mean like, it wasn't always here for people, or maybe it was, I don't know. But like if it wasn't here, I mean that would be so bad!

Interviewer: Why would that be so bad?

Robin: Well, like, I think, like where would people come to learn to ride and be here? Like there's not a lot of places for people in wheelchairs or stuff. There's some, but not a lot. Like some places have ramps and stuff for buildings, but not a lot for kids to do stuff in if they have a wheelchair. Here, it doesn't matter what you can do.

This interaction with Robin shows that even with Ontario's attempts at accessibility for people with physical disabilities, many impediments remain. Robin is keenly aware of the fact that many spaces outside the farm do not allow for full participation by children in wheelchairs. 
Additionally, when Robin was suggesting every person would be happy if they had a horse, she went on to match which horses at the farm would be best suited to each of her immediate family members. Not only was she demonstrating pride in her ability to determine best couplings, but also her empathy for understanding individual horses and people and why these pairings would be best.

Alex spoke of her home life as well, stating that she would "like to bwing [bring] her home wit [with] me, she could live wit [with] me.” Alex explored interest in having a horse in the home as a pet since the family had no pets in the home. It seemed like she wanted the joy she gets from being with the horses to continue to her home as well. Taylor similarly wished for more time with the horses in a different location by talking about it being "cool" if his favourite horse could live in his backyard. He explained that he would spend time with the horse when his siblings were "bugging" him. He sees not the farm as safe space, but the horse itself as one as well.

\section{Summary}

When we return to the research question guiding this study: how do children with mental health concerns perceive their experiences with equine-assisted therapies? we find that the children spoke of their experiences with the horses as positive for their physical and mental health. They also spoke about the special relationships they have with the horses and how these relationships have benefitted the children's lives. The negative aspects of being at the farm had largely to do with things that they knew they could not change, but that they recognized that they had to 'get used to', such as the smells. Important to note is that the children are not always riding the same horse from one lesson to the next. Due to scheduling and availability of a horse (if a horse is lame, they may not be used for therapies until they are healthy again), sometimes children will 
have to ride different horses on a regular basis. Robin discusses her experiences with Skittles and Buttercup because she has experiences with both of the horses.

Regarding their experiences with the space and place (the farm), the children had an appreciation for the social aspects that they identified as benefits mostly for others. They made incredible connections to their lives outside of the farm, seeming to consider the farm a place of acceptance and opportunity often denied to them in their school, home, and/or community settings. 


\section{CHAPTER 6. DISCUSSION}

During the interviews, the children chose to engage in various activities to express their experiences at the farm (See Appendix VI). Three of the children started by drawing, one started at the toy farm, and one chose not to do anything but talk. Interestingly, the four children who engaged in the art and toys flowed between activities and did not remain at one for the duration of the interview. Robin, who did not have confidence in her ability to draw a horse decided to use a toy horse to trace an outline. The melding of the activities and flow between them was an unexpected finding of the project. I was intrigued to note how the children engaged in the activities (even with the child who wanted to only talk) while exploring their perspectives on their experiences at the farm.

The children that I interviewed spoke about many aspects of how their lives have been impacted since engaging in EAT/I. Predominantly they spoke of the emotional connections they had with the horses, the social aspects of life at the farm, and connections they made with other lived experiences outside of the farm. These topics will be explored further with respect to how they contribute to existing literature. This will be followed by the implications of this research and future directions for research.

\section{Emotional Connections with Equine-Assisted Therapies and Interventions}

The emotional connections the children have with the farm were evident throughout much of the interviews. The children expressed positive emotional development at the farm, which supports findings by Boyd and Leroux (2017) who explored equine therapies from the point of view of the parents of children who accessed them. The parents noted improved self-regulation and a calming of their children. Similar findings were drawn from work by Coholic et al. (2019) who found the alternative therapy of arts-based mindfulness had a calming effect on youth with 
mental health concerns. This is interesting to note as pharmaceuticals for children with ADHD, like Ritalin, often aim to calm the patient and help them focus (Charach et al., 2013).

The findings in my research support the findings of Boyd and Leroux (2017), who noted that emotional connections went beyond feeling positive or negative about the experience of EAT/I to demonstrate an improved self-concept. Similar research has found increased selfconfidence, self-efficacy, self-esteem, and importantly, a sense of belonging (Boyd \& Leroux, 2017; Smith-Osbourne \& Selby, 2010; Wilson et al., 2017). Again, my research demonstrates these benefits for individuals partaking in EAT/I, as described by the children themselves.

Research by Wilson et at., (2017) found that it is the non-threatening nature of EAT/I that individuals can improve their ability to reach a goal. The horses allow for the safe practice of skill development in the social and emotional domains without judgement or recourse. The findings in the research by Wilson et al. (2017) is supported by the current study's findings which similarly articulated the nature of EAT/I for attaining goals, and further explained that the non-threatening nature of EAT/I make the programs enjoyable.

\section{Social Experiences with Equine-Assisted Therapies and Interventions}

Previous research has demonstrated improved socialization skills, better awareness of space and boundaries, and a decrease in negative behaviours for children attending therapeutic riding farms (Boyd \& Leroux, 2017; Smith-Osbourne \& Selby, 2010; Wilson et al., 2017). Findings from the current study suggest that EAT/I have positive impacts on children's social development. While the children spoke of friendships and acceptance with the horses, largely the conversations leaned toward discussing the benefits to other individuals participating at the farm. The children perceived benefits to themselves and others at the farm is framed as a safe space to practice 
social skills without judgement. The horses cannot speak back and are non-judgmental. This adds to the current literature by acknowledging the prosocial skills involved with therapeutic riding.

Other research has argued that it is the power dynamic inherent between a client and instructor/therapist that inhibits development (Wilson et al., 2017). It is only when a horse is introduced to mitigate this power hierarchy that individuals can develop trust and engage with their therapy. Much research into social skills development with EAT/I has been focused on children on the autism spectrum (Anderson \& Meints, 2016; Srinivasan, Cavagnino, \& Bhat, 2018; Tan \& Simmonds, 2018). Consistent with past studies, findings from the current study have provided evidence for perceived improved social skills.

Similarly, work by Srivinasan et al. (2018) suggest that social development is tied to well-being which complimentary treatments such as EAT/I can provide. The findings in this study confirmed this and extends the literature by challenging how a sense of belonging is developed. In the school setting, it appears simply being present with others is considered adequate for providing a sense of belonging to children. However, my findings demonstrate that children need to feel supported, given opportunities to fail and try again without punitive action, and have leadership opportunities. The smallest of accomplishments, when celebrated, appear to be incredibly empowering for the children.

\section{Connections to Other Lived Experiences}

The most unexpected findings in my study were the children's desire to connect and compare their experiences at the farm to their experiences outside of the farm. Primarily they referred to experiences at school and with teachers, and some of these were not positive - a sharp contrast to what they experienced at the farm. My findings were not unlike D'Eloia and Price's (2018), who 
found that children who participated in a summer camp solely for children with disabilities provided the children leadership opportunities often denied to them at school.

The flawed attempts at inclusion at school that the children in my study revealed were very similar to those identified by D'Eloia and Price (2018) who noted that some types of 'inclusion' in schools leave children with disabilities feeling excluded and stigmatized, and without the ability and opportunity to develop sustained friendships (Normand et al., 2013). The children that I interviewed sharply contrasted their experiences in their school setting from those at the farm, supporting previous research and highlighting the failed attempts at inclusion in most schools (D’Eloia \& Price, 2018; Normand et al., 2013). The children confirmed that with EAT/I, children with mental health concerns are able to practice social skill development in a safe manner without chastisement.

I learned through the children that a safe space to take risks and learn in a supportive environment is crucial to skill development, and the ability to grow socially, physically, emotionally, and cognitively. The more children have opportunities to practice, the better they can become. The more a child is isolated and stigmatized, the less a child will learn.

\section{Author's Reflection}

In the methodology section, I highlight the complexity of conducting research with children. I employed a multi-faceted approach for self-expression to engage the children during the interview process. What I was not prepared for was the power of control in the interviews. As an athlete, I learned to visualize my successes, to ensure that I keep moving towards my goals. So, for my first interview, I visualized how it would successfully unfold. By ensuring I was affording the children the opportunity to guide the conversation, I had assumed the semi-structured interview questions would be used as a flexible guide to redirect any tangents the children may 
wish to explore. I quickly learned that these tangents are critical to letting children guide the conversation. I had planned and prepared the interview space, tools, and questions, and almost immediately in the first interview I had to quickly adapt. The morning of my first interview with Jamie, a beloved cat at the farm had died, which made some children upset. At first, I attempted to be stringent on the design of the interviews, but once I became flexible and learned to let go, I discovered new and interesting ways the children presented their ideas, thoughts, and perspectives. I realized that I had to let myself let the children guide the process and allow them to rule the experience. This concept of methods and chaos is important for me to remember as I move forward in my work with research.

Reflecting on my experiences has fortified my belief that children are agentic, competent, and capable in the research process. They carry unique and valuable insights that need to be explored and embedded into policies and programming. Children with disabilities are not a separate category of children, and so should be included in all research and policy development that includes and respects the voices of children. In the future, I believe it would be beneficial to adopt more strategies for data collection with children, including theater, media, puppet shows, dramatic play, exploration of environments and much more.

\section{Implications}

The findings in this study may be of value for the development of program and policies at this farm and others. The children have demonstrated not only their competency and ability to partake in research and give their opinions on matters impacting them, they have also demonstrated their desire to be included in such developments. This research shows that an examination of programs and policies connected to EAT/I that are currently directed at children would benefit from input from the children themselves. Additionally, this study supports research 
by Koller (2016), who argues that children should have a voice and a choice in their healthcare plans.

\section{Future Directions and Limitations}

In line with a combined sociology of childhood and a children's rights perspective, future studies can and should be conducted to ensure children's rights are being met and children are present in research and policy development. Document analyses for programs directed at children with mental health concerns should be done to determine if children's voices are present in matters impacting them, as is their right (United Nations, 1991). Research directed at family quality of life would be beneficial as well, addressing the views not only of the parent or child, but of the family as a unit (Wang \& Brown, 2009).

Research investigating long term outcomes of engagement with EAT/I will be very beneficial to supporting its use. For example, studies could examine longer-term academic performance and outcomes for children who engaged with EAT/I, or include a control group where children were offered EAT/I. Similarly, research examining truancy, hospitalizations, socio-economic status and more, could help determine if EAT/I have beneficial long-term outcomes for a wider range and more diverse group of individuals with mental health concerns. Comparative research may find differing outcomes for children with emotional concerns compared to those with behavioural disorders.

Research into inclusive practices in schools and other contexts in which children live must be done to challenge the pitfalls and elevate, celebrate and emulate the more successful practices. This will be beneficial to ensure children are not being stigmatized and discriminated against, and are being afforded the opportunities for leadership, development, and practicing skills they deserve. These strategies can be simple, affordable, and effective. For example, 
Maich, Davies and van Rhijn (2019) argue that simple alterations to a classroom can have important impacts. The authors suggest creating a 'relaxation station' in classrooms to help with self-regulation and sensory needs. This creates a more accessible space for children with disabilities and for those without. Additionally, van Rijhn et al. (2019) conducted research into the efficacy of peer-mediated interventions, demonstrating improved social skills and less problem behaviours, while the control group demonstrated an increase in bullying behaviours. This simple and cost-free intervention is beneficial to all children. As teachers often have many students and limited funding, further research into simple and cost-effective classroom strategies can support teachers in developing more inclusive, child-focused classrooms.

As critical disability studies teach us, research that decolonizes and challenges the notion of 'disability' and personhood can help disrupt pathologizing and 'othering' concepts of people with disabilities. Research by Stienstra and Ashcroft (2010) has already begun this process by using the notion of spirit and spirituality to broaden the understanding of the human experience. Future studies may also wish to address new ways of conducting research with children, to help deconstruct and disrupt the power dynamics which exist between researcher and childparticipants. Gerlach (2018) offers decolonizing methodologies for colonial-settler researchers to be applied to research with marginalized children and youth. Decolonizing methodologies are crucial to research in Canada, especially given the Indigenous-settler social, political, moral and historical contexts. Palley et al. (2010) suggest EAT/I are becoming more popular with a push from advocates preferring non-conventional medical practices. Research into the merits of EAT/I may help to more fully integrate them and make them more widely accepted in mainstream medical practices. 
A number of limitations exist in this study; therefore, future researchers may wish to address these limitations. This study was limited by the low number of participants and the fact that it focused on one farm. Future research may wish to explore children's perceptions of EAT/I with a larger sample size and using comparisons, across a range of farms. Similarly, future research could include a wider age range to gather a more complete understanding of how children perceive their experiences with EAT/I. It also would be beneficial to conduct community-based participatory research to develop collaborative partnerships and actively involve the children in all aspects of the research (Leavy, 2017). Finally, research into how policies and programming have changed once they have included children's voices would be beneficial to supporting the active involvement of children in research, and policy and programming development. 


\section{CHAPTER 7. CONCLUSION}

This study supports the inclusion of children in the policy and programming development at a therapeutic riding farm in Ontario. Using a sociology of childhood framework, the children in this study were conceptualized as competent and agentic, which the findings sustained. Understanding how children with mental health concerns perceive their experiences with EAT/I is important on multiple levels. First, the children, as the clients, deserve to have input on the programming in which they are participating. Second, the children must believe they are benefiting from the treatments and interventions in which they engage to understand why continued participation is important. Third, by participating in research to understand their views and opinions, children with mental health concerns can demonstrate their competency and agency throughout the research and healthcare processes.

This study provides a basis for further exploration in research with children, and with alternative treatments for individuals with mental health concerns. Further research into how children with mental health concerns perceive alternative healthcare treatments such as EAT/I may help to ensure children's voices are respected, included, and are evident in healthcare, policy, and program development. We also see that we have a lot to learn from the children. 


\section{Appendix I: Approval Letter from Board of Directors}

April 21, 2019

Dear Erin,

Thank you again for reviewing your research proposal with the Board of Directors last

Wednesday. I'm happy to inform you that we are granting approval for you to proceed with your research project as presented and discussed. With this letter, we also acknowledge that you are permitted to take photographs of the horses and ponies as part of your work.

We wish you all the best in conducting your research. We also look forward to hearing about any results that come from it.

Regards,

(Name Omitted to maintain confidentiality) 


\section{Appendix II: Recruitment Flyer}

Note: Parts of the Flyer have been altered from the original to protect the identity of the farm.

\section{Ryerson}

University

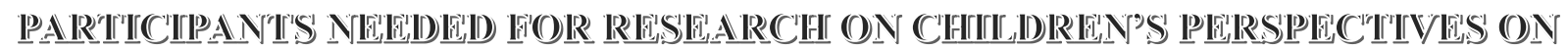

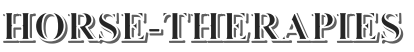

Are You or Do You Have A Child Who Is:

- Between the ages of 4 and 12 ?

- English-Speaking?

- Enrolled in equine-assisted therapies (therapeutic riding) at (NAME OMITTED) and have had at least one session?

If you answered yes to these questions, I'd like to invite you to volunteer in this study of exploring children's experiences with equine-related therapies

10 participants will be asked to join me in play and art-based activities while answering questions about their experiences at the farm.

Sample questions include:

- How long have you been coming [here]?

- What do you do there?

- What is your favourite thing about [here]?

Participation will involve one 30-minute audio-recorded interview to take place in a private room at [the farm]. Participation will be confidential. You or your child may opt-out of being audiorecorded.

If you are interested in participating in this study or for more information, please contact:

$$
\begin{gathered}
\text { Erin Harvey } \\
\text { Graduate Student } \\
\text { Department of Early Childhood Studies } \\
\frac{\text { elharvey@ryerson.ca }}{\text { Please respond by May 15 }} \text {, } 2019
\end{gathered}
$$

This research study (2019-090) has been reviewed and approved by the Ryerson University Research Ethics Board 


\section{Appendix III: E-mail}

\section{E-mail Confirmation}

Dear (Parent Name),

Thank you for reaching out regarding the research study flyer posted at the farm.

Attached to this e-mail is a blank consent form (for you) and a blank assent (for your child) with

further details on what to expect from the study. These are yours to keep. Please review these and contact me with any questions you may have. If after reviewing these forms you and your child are interested in participating in the study, please contact me and we will set up a time to meet at your convenience. At the meeting, we will review the consent and assent forms together before beginning the interview and I will answer any questions you may have.

Thank you again and have a great day, Erin Harvey 


\section{Appendix IV: Consent Form}

Note: Parts of the Consent Form have been altered from the original to protect the identity of the

farm.

Your child is being invited to participate in a research study. Please read this consent form so that you understand what their participation will involve. Before you consent for your child to choose to participate, please ask any questions to be sure you understand what their participation will involve.

\section{TITLE OF THE PROJECT}

How children with cognitive disabilities ${ }^{8}$ perceive equine therapies: Assessing treatment from first-hand experiences of children

\section{$\underline{\text { INVESTIGATORS }}$}

This research study is being conducted by Erin Harvey, a Master of Arts student in the School of Early Childhood Studies, in partial completion of her Masters in Early Childhood Studies. She is being supervised by Dr. Patrizia Albanese from the Department of Sociology at Ryerson University. Erin is a previous member of the board of directors at [the farm], but no longer holds a position.

If you have any questions or concerns about the research, please feel free to contact Erin Harvey at e1harvey@ryerson.ca

\section{$\underline{\text { PURPOSE OF THE STUDY }}$}

${ }^{8}$ After the REB had approved this form, during the analysis, the study changed to encompassing mental health concerns more broadly, and not solely cognitive disabilities. Additionally, the term 'disability' was not used for reasons mentioned in Chapter 3: Theoretical and Conceptual Frameworks. 
The study aims to investigate how children aged 4-12 years old with a cognitive disability perceive equine-assisted therapies at [the farm]. Five to ten participants will be recruited for this study and must be verbal, English speaking children who are enrolled in programming at [the farm]. The results will contribute to a major research paper for the degree requirements of the investigator and for publication, for conference presentations, and photographs will be taken to create a picture book with quotes attached for the therapeutic riding farm to retain.

\section{WHAT PARTICIPATION MEANS}

\section{Your Role:}

If you allow your child to choose to participate in this study, you will be asked to do the following things:

- Organize a time with the investigator for an interview session

- Be present during a one 30-minute interview with the child at the farm

- Help to ensure that your child is aware they can withdraw from the study at any time

- Help to ensure that child understands what is being asked of them

- If you and your child agree, provide consent for the interview with your child to be audio recorded. Should your child choose to not be recorded, written documentation will be used to capture the dialogue of the child.

- If you and your child agree, allow the investigator to photograph your child's drawing or play activities to be used, without their name, in the analysis and write-up, and dissemination of information to the farm

For your child

If you agree (signed consent) your child will be invited to:

- Review and sign the assent form prior to the interview

- Draw pictures of the horse (and other objects of interest) they interact with at [the farm], or alternately, play with toys of their choosing

- Answer questions about their horse, their experiences at [the farm] (For example: What they do at [the farm]; What they like most and what they like least)

- Allow the investigator to photograph any drawings or play activities. No photographs will be taken of the child

- Allow the investigator to audio-record our interview

\section{POTENTIAL BENEFITS}


While your child may enjoy drawing and talking about [the farm], I cannot guarantee any personal benefits to them or to you. My goal is to ensure that the voices of children with cognitive disabilities are part of these discussions and can help inform the literature and practice in this area, but given the small sample size, I anticipate making only a modest contribution towards this end.

\section{WHAT ARE THE POTENTIAL RISKS TO YOU AND YOUR CHILD AS A PARTICIPANT?}

As you are aware, children playing at a farm may result in physical injury. However, this research will take place away from the horses, in a private room at the farm where there is no dangerous equipment.

Being with an unknown adult (the investigator) may cause stress and speaking about their experiences with horses and/or peers at the farm may raise memories that your child may not wish to revisit. If you or I sense that this is the case, I will skip any question or stop the interview.

Your child may also talk to friends or family outside of the study about the interview, which may breach confidentiality. It will be asked that you and your child do not speak about your participation outside of the study.

If you or your child find any part of the interview uncomfortable, I can stop the interview at any time and not use anything that I collected as part of my study.

\section{CONFIDENTIALITY}

In order to protect your identity and that of your child, the name of the farm will not be used in publications, nor will your name or your child's name. When writing my results, I will use pseudonyms. All electronic data (transcripts of the audio-recordings and photographs) will be kept encrypted and password protected, on a private server. Audio files will be kept until they are 
transcribed and verified and then immediately destroyed/deleted from the recording device.

Electronic photographs will be deleted after they have been used for data dissemination. Signed consent and assent forms will be kept in a locked filing cabinet in a locked office in my home for the period of one year. After the period of one year, all physical and electronic data will be shredded/deleted/destroyed.

Please note that as a registered early childhood educator I am required by law to break confidentiality if the duty to report arises. I have the duty to report the following cases;

i. If your child intends to harm them self;

ii. If they intend on harming someone else;

iii. If there is reasonable suspicion that a child up to the age of 16 years is at risk of neglect of abuse, I am required by law to report this to the Children's Aid Society right away;

iv. If my files are subpoenaed by the courts (records can be opened by specific court order);

v. If a regulated health professional has engaged in inappropriate sexual behavior toward your child and your child provides me with the name of the individual, I am obliged to report them to their regulatory body.

\section{VOLUNTARY PARTICIPATION AND WITHDRAWAL}

As a parent of the participant, you have the right to withdraw your child from the study at any time without reason, with no questions asked. Additionally, your child has the right to withdraw at any time.

Participation in this study is entirely voluntary. You can consent whether your child can choose to be in this study or not. If any question makes you or your child uncomfortable, we can skip that question. You may stop participating at any time. Your child may stop participation at any time by either verbally requesting a stop, or through the use of body language to make obvious they wish to stop. If you or your child choose to stop participating, all data collected thus far will be destroyed. Your choice of whether to participate will not influence your future 
relations with the Ryerson University, the School of Early Childhood Studies, Erin Harvey, Patrizia Albanese or [the farm].

The results of this study will be shared in two picture books of the children's drawings, horses at [the farm] and quotes, one copy for [the farm], one copy for the research paper. A copy of my final research paper will also be available in Fall 2019 and can be accessed via Ryerson University's digital repository. The paper may be used for conference presentations, for publication, and for admission requests to $\mathrm{PhD}$ programs by the researcher.

\section{QUESTIONS ABOUT THE STUDY}

If you have any questions about the research now, you may contact:

Erin Harvey

Graduate Student

E-mail: e1harvey@ryerson.ca

This study has been reviewed by the Ryerson University Research Ethics Board. If you have questions regarding your rights as a participant in this study, please contact:

Research Ethics Board c/o Office of the Vice President,

Research and Innovation

Ryerson University 350 Victoria Street

Toronto, ON

M5B 2K3 416-979-5042

rebchair@ryerson.ca

How children with cognitive disabilities perceive equine therapies: Assessing treatment from first-hand experiences of children 


\section{CONFIRMATION OF AGREEMENT}

Participants are informed that by signing the consent form you are not waiving any legal rights in the event of research-related harm. Your signature below indicates that you have read the information in this agreement and have had a chance to ask any questions you have about the study. Your signature also indicates that you agree to allow your child to choose to participate in the study and have been told that you or your child can change your mind and withdraw consent to participate at any time. You have been given a copy of this agreement. You have been told that by signing this consent agreement you are not giving up any of your legal rights.

I give consent for my child to choose to be audio-recorded and have their work photographed (no photo of your child's face or any other identifying features will be taken/included) for the purposes of this study. I understand how these recordings will be stored and destroyed. Please initial to indicate consent:

I give consent for my child to choose to be audio-recorded for the purpose of this study I give consent for my child to choose for their work to be photographed (no images of your child's face or other identifying features will be included in any dissemination).

I give consent for my child to choose to have the photographs of their work shared with [the farm] and as part of the researcher's study 
Name of Child

Signature of Parent/guardian of Participant 


\section{Appendix V: Assent Forms}

Note: Some of the dialogue has been altered from the original to protect the identity of the farm.

Note: The investigator will complete the assent forms with each child. The parent/guardian may assist as well if the child wishes.

My name is Erin and I'm working on a school project on your time here at [the farm].

For my school project I'd like to ask you to draw with me and answer some questions about what you do at [the farm]. Does this sound okay so far? (If they choose not to draw, toys will be available for use, or they may wish to only talk)

We will draw and talk for about 30 minutes, but you can stop at any time. You can also not answer any of the questions that I ask, if you don't want to answer.

Your mom/dad will be here in the room with us as well so you can tell them if you want to stop. If it's okay with you, I would like to record what we talk about so I can listen to it later. Is this okay? If not, I will have to take notes while we talk, ok?

I'm going to use what you tell me and what you draw to write a story about what you do at [the farm]. Is this okay with you?

And if it's okay with you, can I take a picture of your drawing (or play), so I can use it for the story that I'm going to write? Is this okay? If not, we can talk, and I won't take any pictures. Is it ok if I share these pictures with others?

I want you to know that we can stop at any time. You can let me, or your mom/dad know, and we'll stop. Do you understand?

Is it okay if we start? 
Do you have any questions for me?

Can you write your name?

If you think it's okay for us to start drawing, can you write you name here:

My Name

You can ask me questions

YES

NO

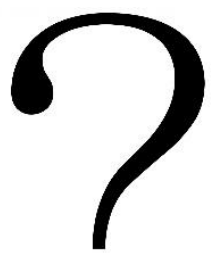

0

My Name

You can record my voice YES

$\mathrm{NO}$

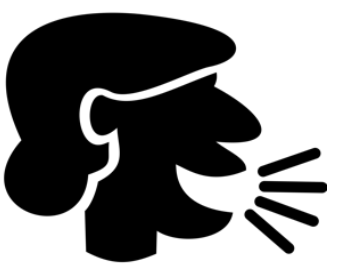


My Name:

You can take pictures of my work

YES

NO

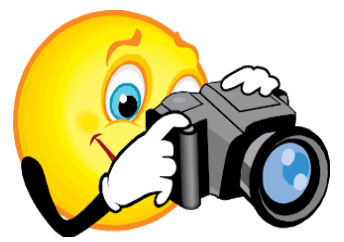

My Name:

You can share the pictures you take of my work with others

YES

NO

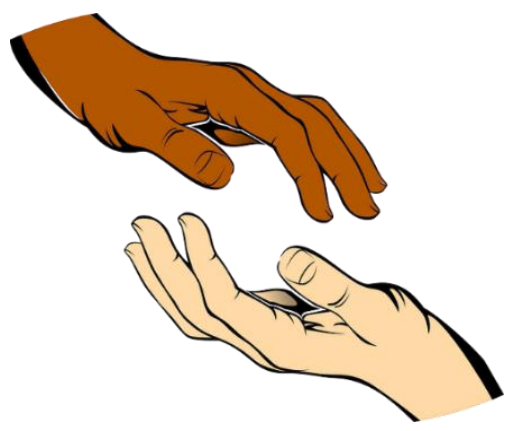




\section{Appendix VI: Location Layout}

$\underline{\text { Farm Layout }}$

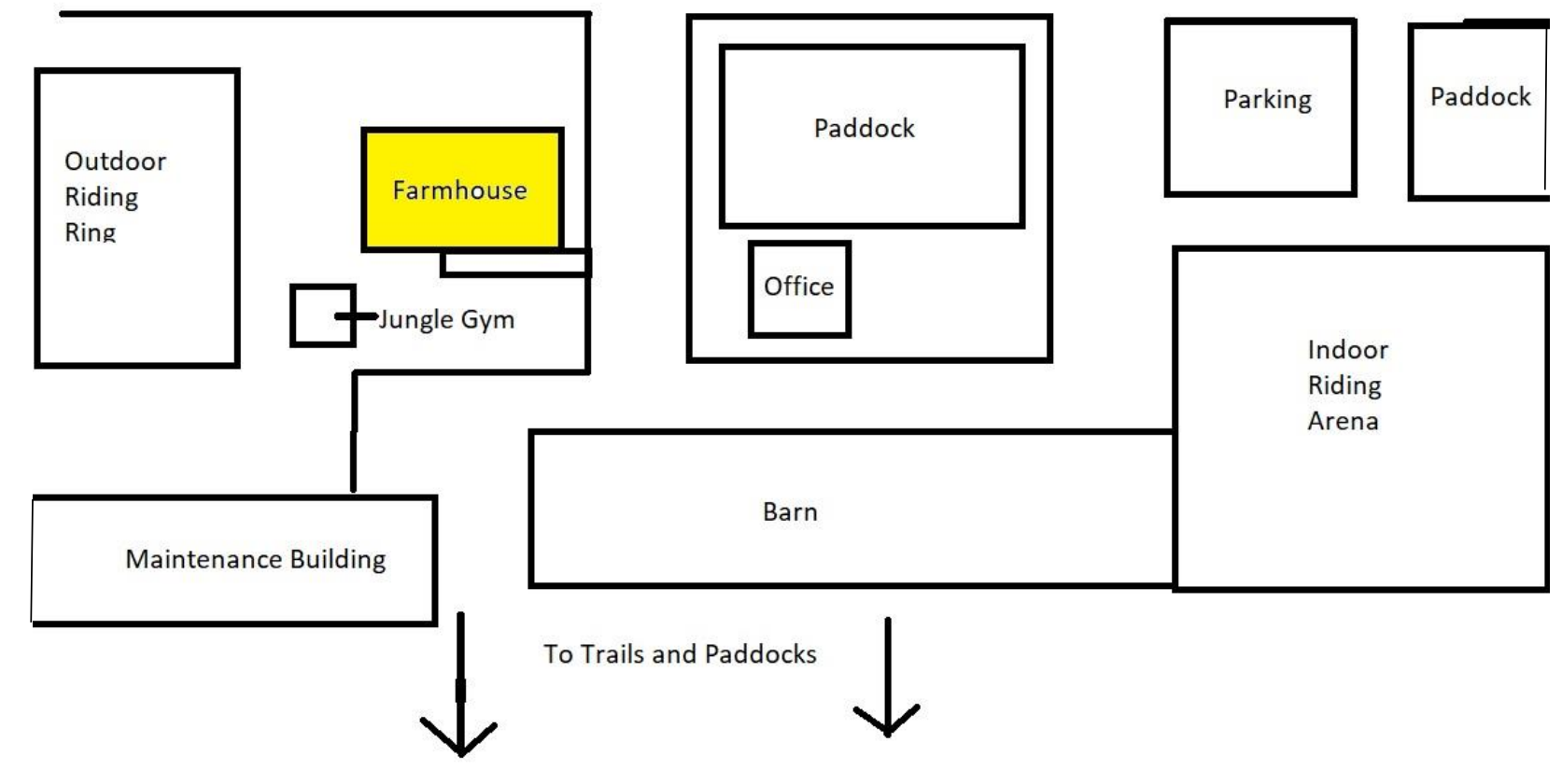

$\underline{\text { Farmhouse Layout }}$

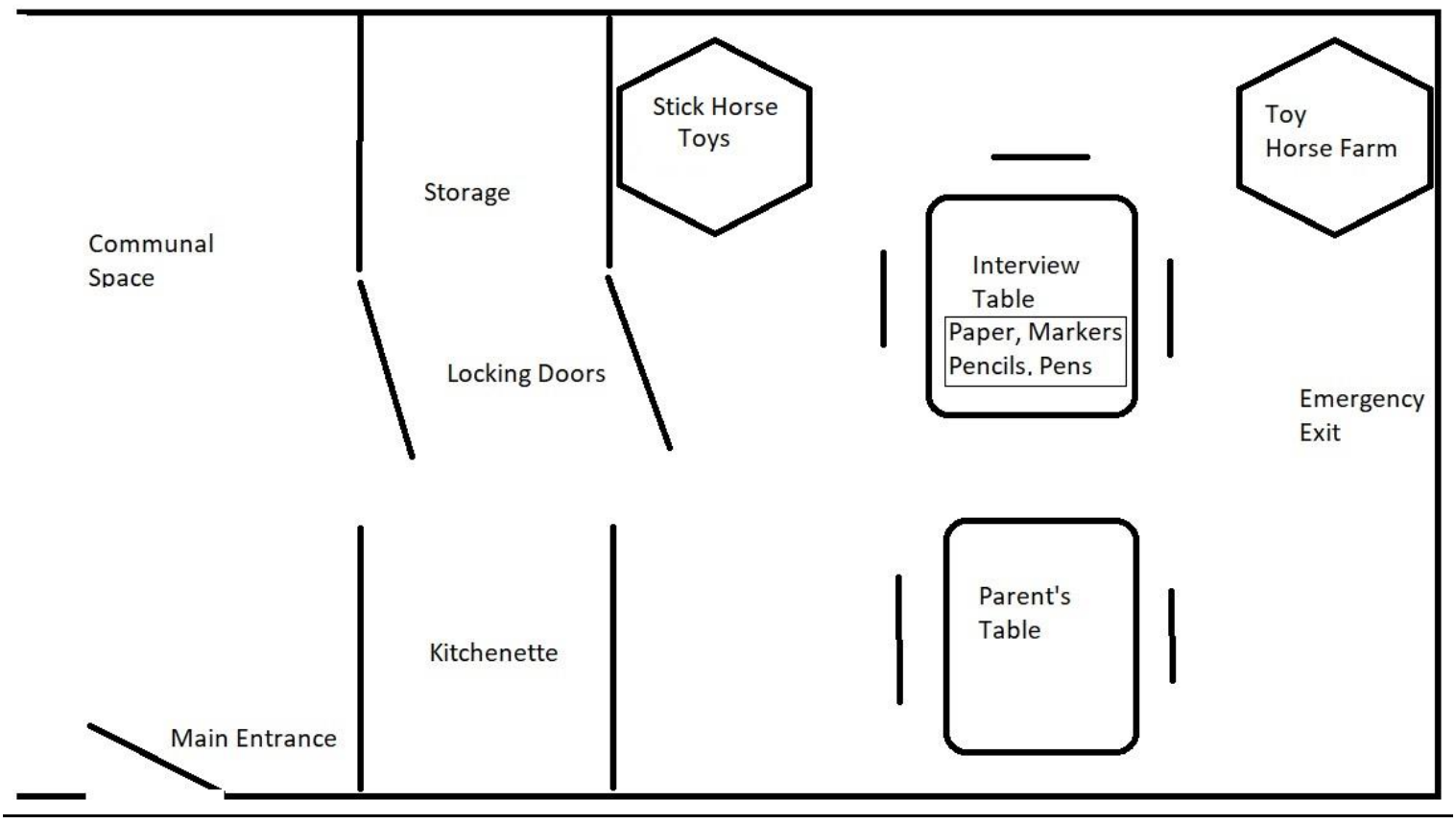




\section{Appendix VII: Interview Questions}

Note: Some of the questions have been altered from the original to protect the identity of the

farm.

Erin Harvey

Interview Questions:

1. There is lots of stuff to draw with here. Do you want to draw a picture of the farm with me?

a. If yes, the child can begin to draw

b. If no, the child can play with toys or converse without another form of selfexpression

2. Can you draw a picture of the horse you play with?

a. Is there anyone or anything else you want to draw with your horse? Who/what it that?

b. What is this horse's name? Does your horse like any special foods?

c. How long have your known (horse's name)?

3. Have you been coming to the farm a long time?

a. Yes- How did you feel about it here when you started? How do you feel about it now?

b. No- What has it been like starting here?

4. What do you do with (horse's name) when you are here?

5. How does that make you feel?

6. What do you like best about the farm (What is your favorite thing to do here?)

7. What don't you like doing when you are here?

8. What have you learned here at the farm that you use when you're not at the farm?

9. Is there anything else you want to draw or want me to draw with you?

Thank you so much for talking to me. Can I take a picture of your drawings (or play)? 


\section{Appendix VII: Thematic Data Analysis of Findings}

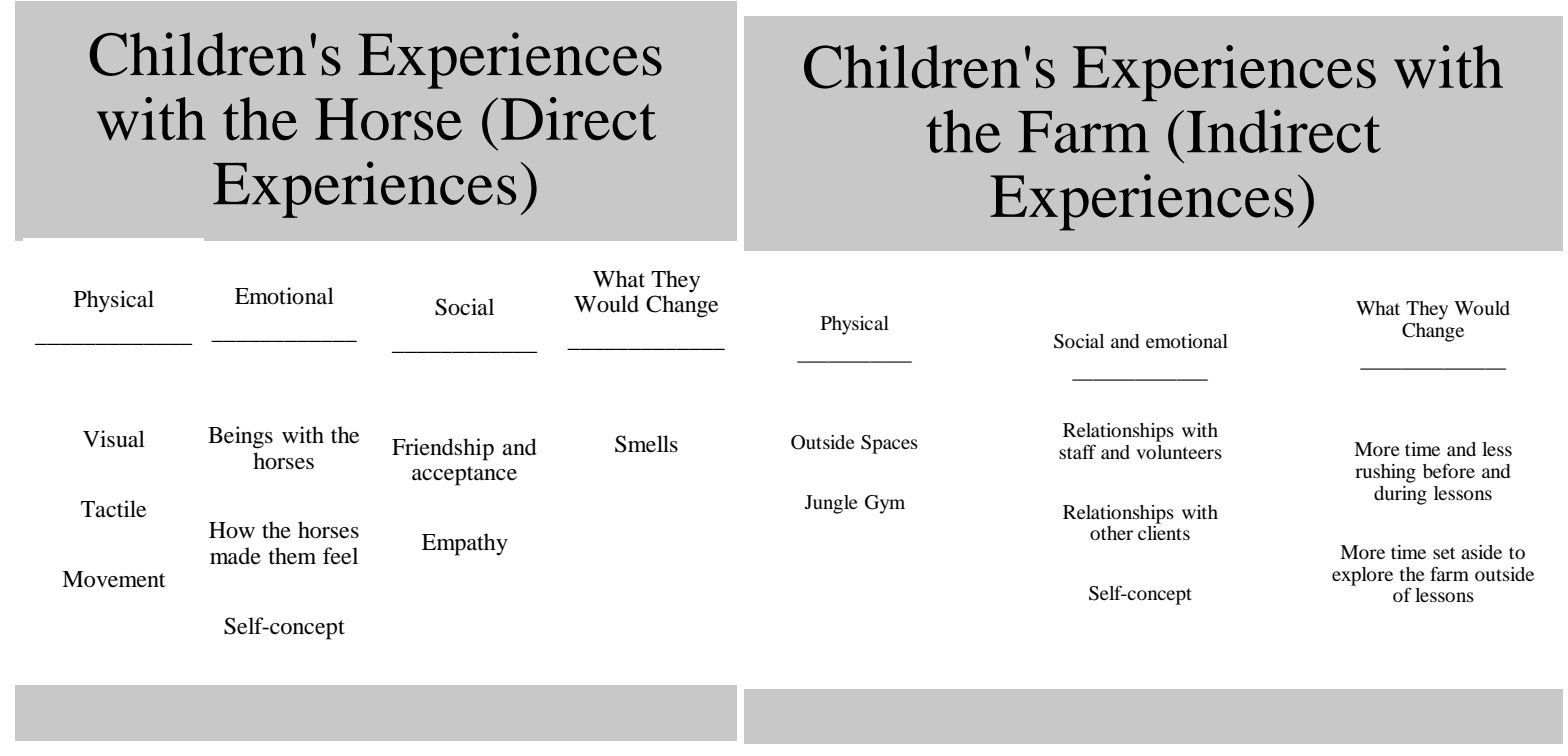

\section{Connecting to Other Lived Experiences}

School

In class

With peers

With relationships with teachers

Power, control and leadership opportunities

\section{Community}

Accessibility

Barriers not seen at farm

horses

Bringing horse into the family as a pet

Horse as a safe space and thing of comfort in the home 


\title{
"It's easier to be with them": How children with mental health concerns perceive their experiences with equine-assisted therapies
}

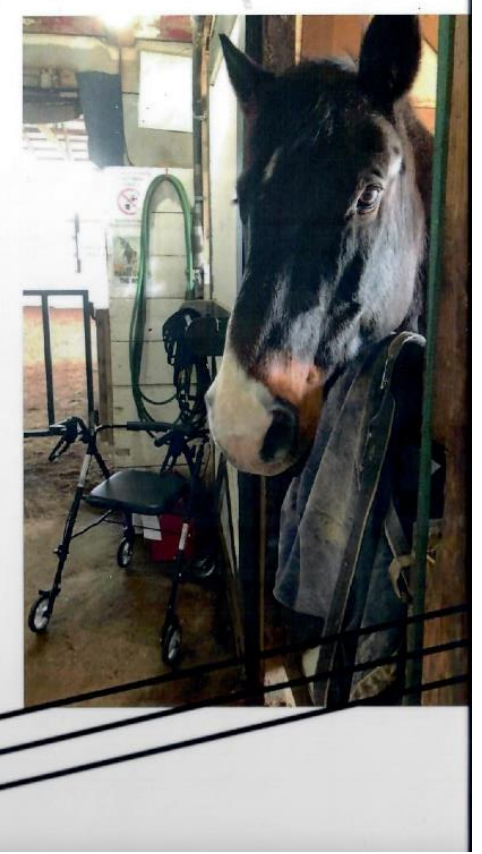

This project is dedicated to all the horses who have shared their love with us

\author{
Erin Harvey \\ Ryerson University \\ 2019
}


Children are often left out of research, so this project wants to know what horse-therapies are like from the people who use it- the children!

By understanding how the children feel about horse-therapies, programs and lessons can be made with input from the children

The researcher (Erin) loves horses and has been riding for over 30 years. She has volunteered at the farm and loves working with children
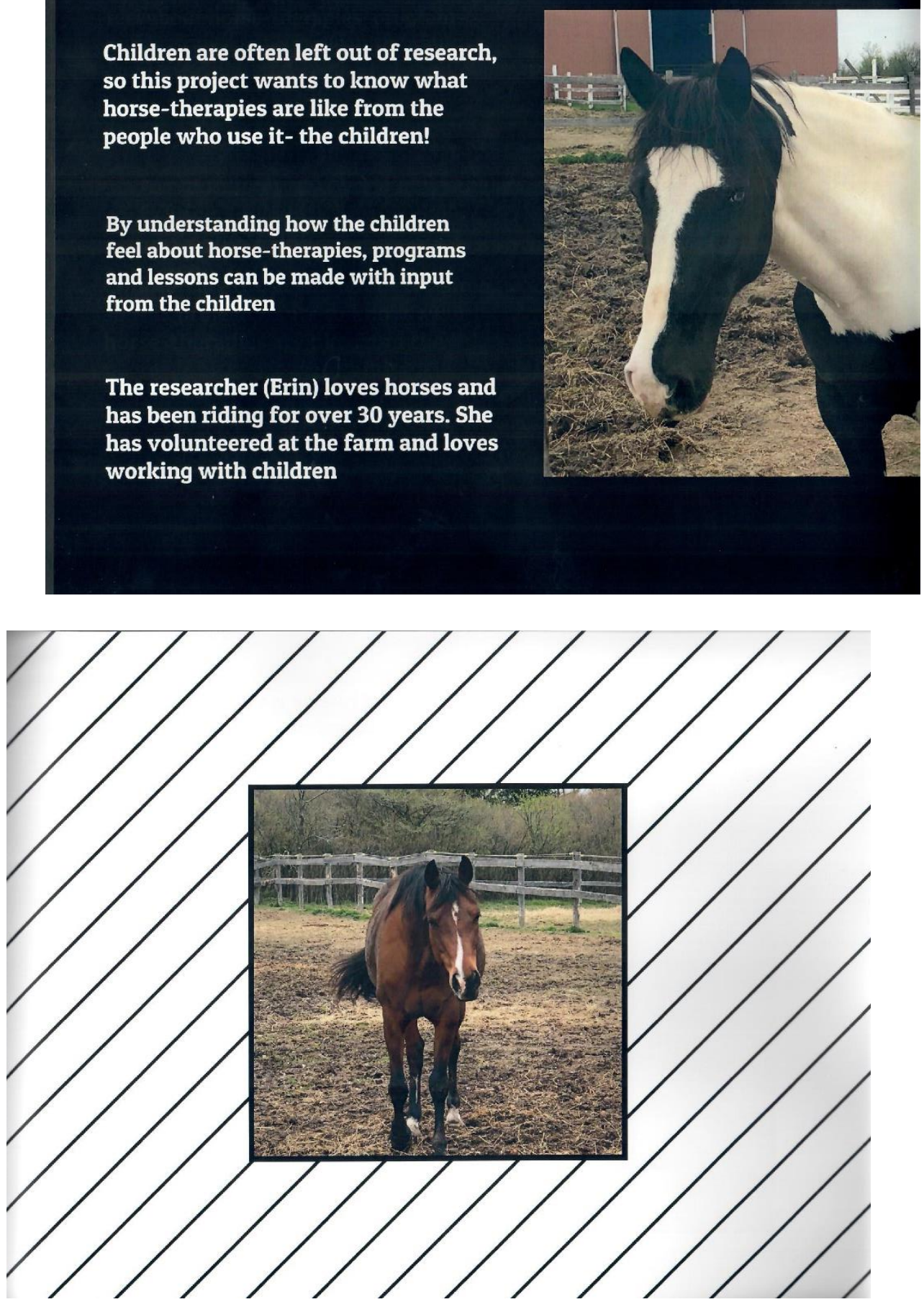
With five children between the ages of five and twelve we explored what they thought of their experiences at a therapeutic riding farm in Ontario.
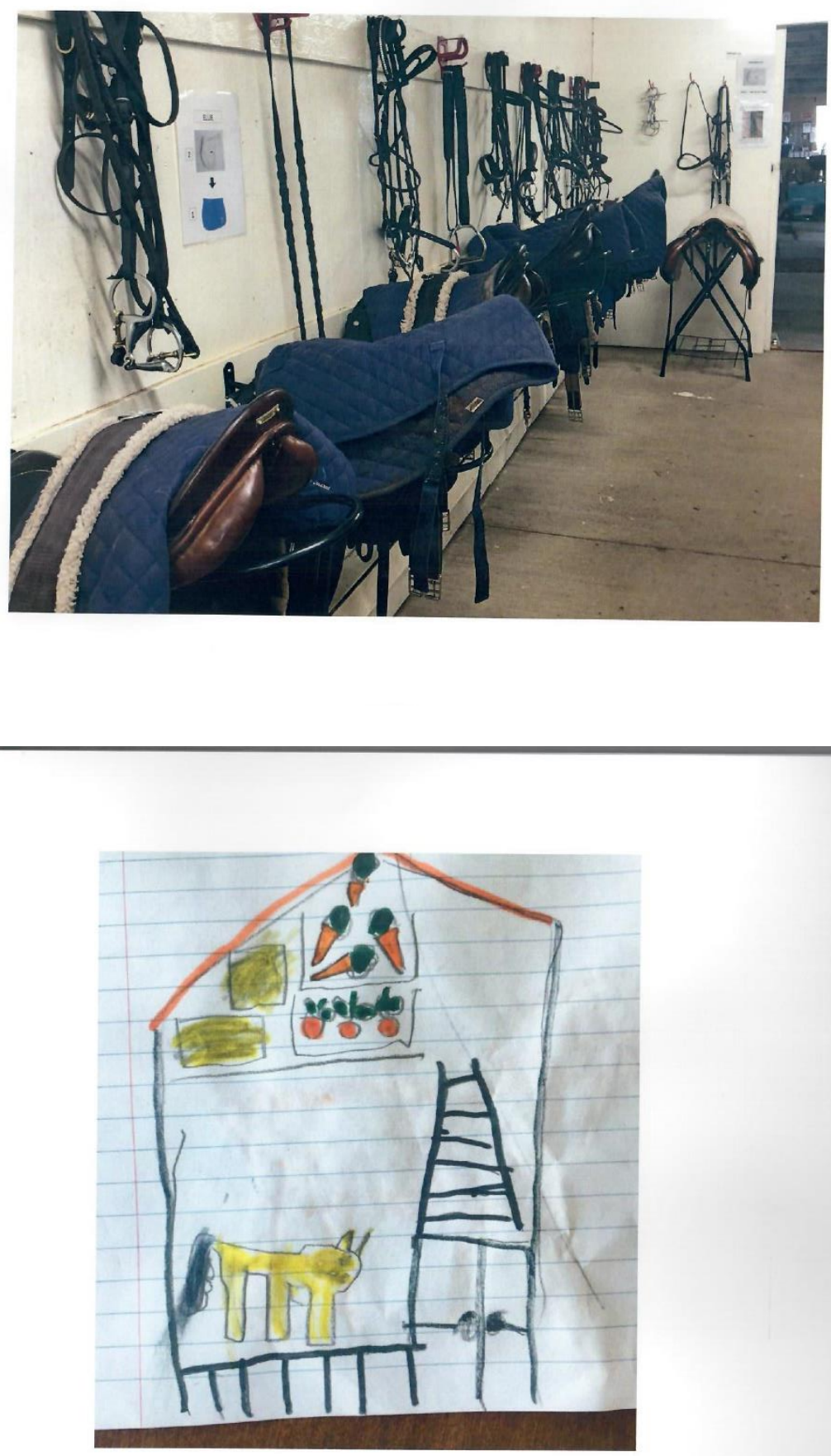

Through art, play, and talk, we explored how they felt at the farm, what they liked, and what they didn't like 


\section{What We Discovered}

\section{Experiences with the Horses}

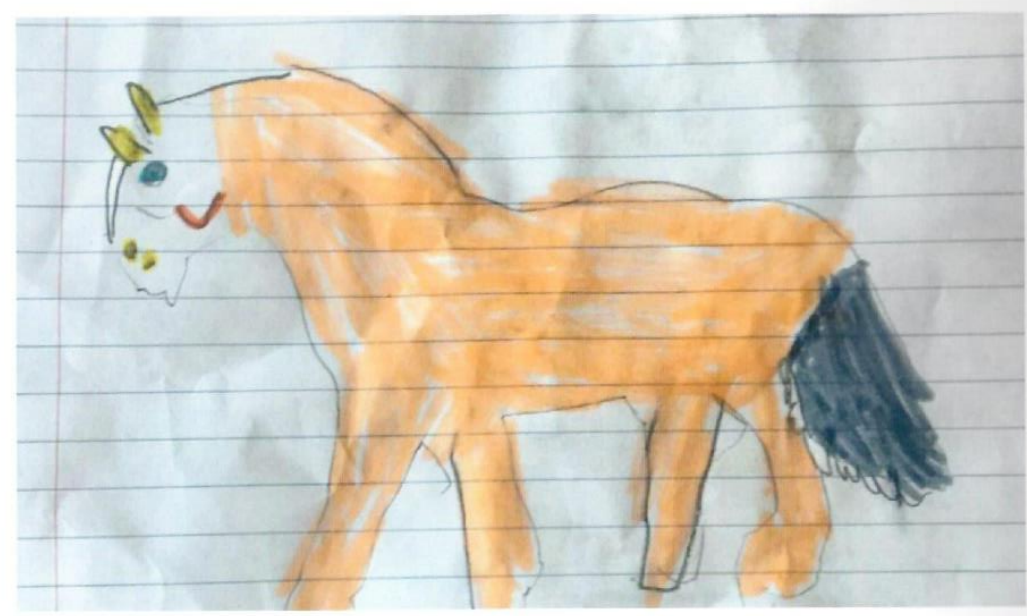




\section{Physical Experiences with Horses}

Touch "I LIKE DEY (THEY) SOFT AND DEY (THEY) WARM. DEY (THEY) FEEL NICE" - Alex

Sight "She'S SUPER CUTE! SHE LOVES ME." - ROBIN

Movement "I CAN HIGH FIVE PEOPLE, OR PUT RINGS ON POLES, BUT YOU GOTTA DO IT WHILE WALKING SO IT'S HARD" - JAMIE

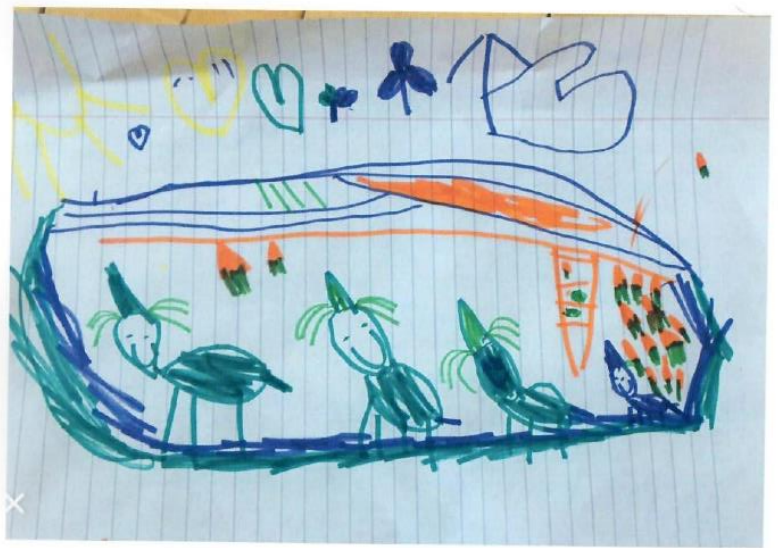

\section{Emotional Experiences with Horses}

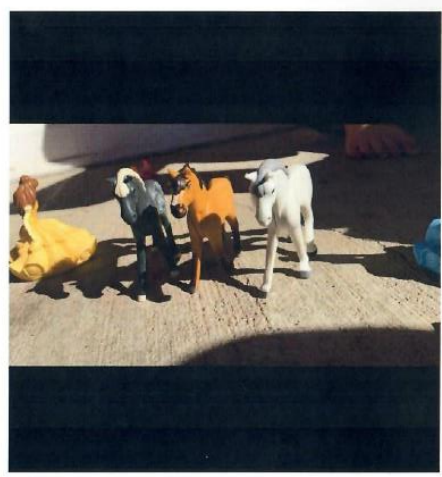

"I SMILE A LOT WHEN I'M HERE. I THINK EVERYONE IN THE WORLD WOULD BE HAPPY IF THEY GOT A HORSE"

- ROBIN

"IT'S EASIER TO BE WITH THEM. THEY DON'T CARE. THEY LIKE, THEY LIKE YOU NO MATTER WHAT! SO LONG AS YOU HAVE APPLES!" - JORDAN

"I FEEL CALMER... I HAVE TO FOCUS... IF YOU DON'T, YOU MIGHT GET KICKED. LIKE WHEN YOU PICK FEET, WITH A HOOF PICK, YOU GOTTA CLEAN THEIR FEET, RIGHT? YOU GOTTA PAY ATTENTION, CUZ IF THERE'S LIKE A FLY ON THEM, THEY MIGHT KICK AT IT AND GET YOU INSTEAD" - JORDAN 


\section{Social Experiences with Horses}

TAYLOR: UMMM, YEAH. I TALK TO HER.

ERIN: WAIT...YOU DON'T TALK TO ANYONE ELSE? EEVER? YOU'RE TALKING TO ME RIGHT NOW. WHAT MAKES HER SPECIAL TO TALK TO?

TAYLOR: UMMM. SHE LISTENS. I CAN TELL HER THINGS I DON'T TELL ANYONE ELSE.

ERIN: THINGS LIKE WHAT?

TAYLOR: I DON'T WANT TO SAY

ERIN: THAT'S OK. YOU DON'T HAVE TO TELL ME ANYTHING YOU DON'T WANT TO, RIGHT?

TAYLOR: YEAH

ERIN: SO WHY DO YOU LIKE TELLING HER THINGS YOU DON'T TELL ANYONE ELSE?

TAYLOR: CUZ SHE LISTENS, AND SHE WON'T TELL ANYONE...

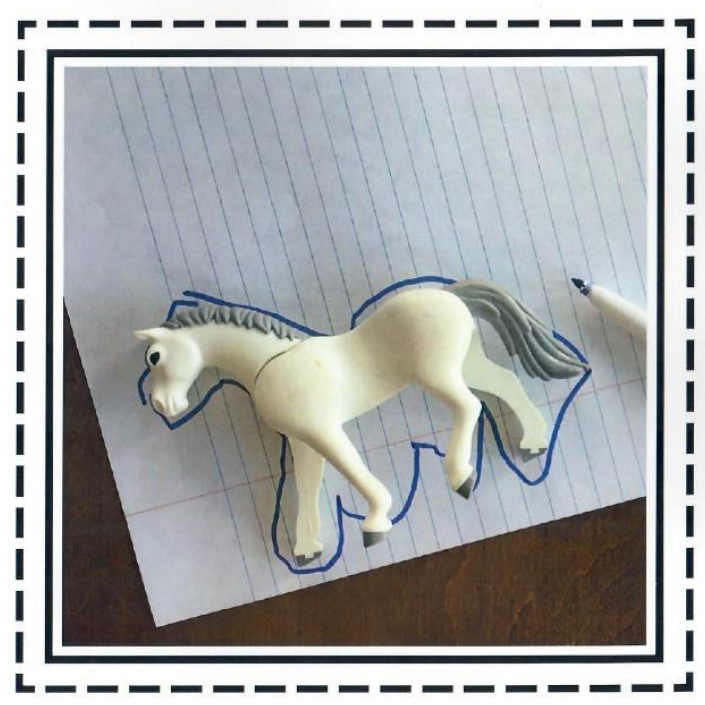




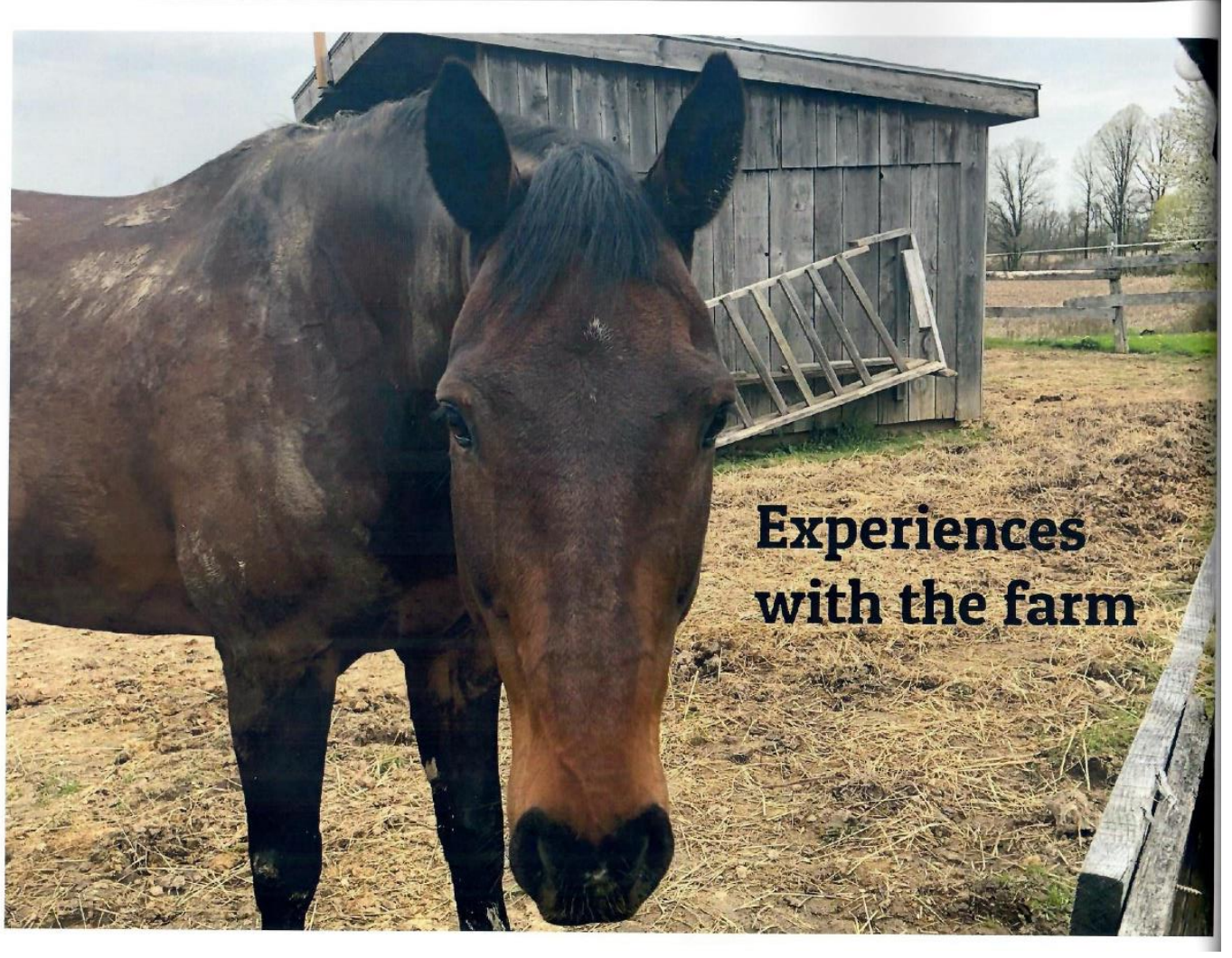

\section{Physical Experiences with the Farm}

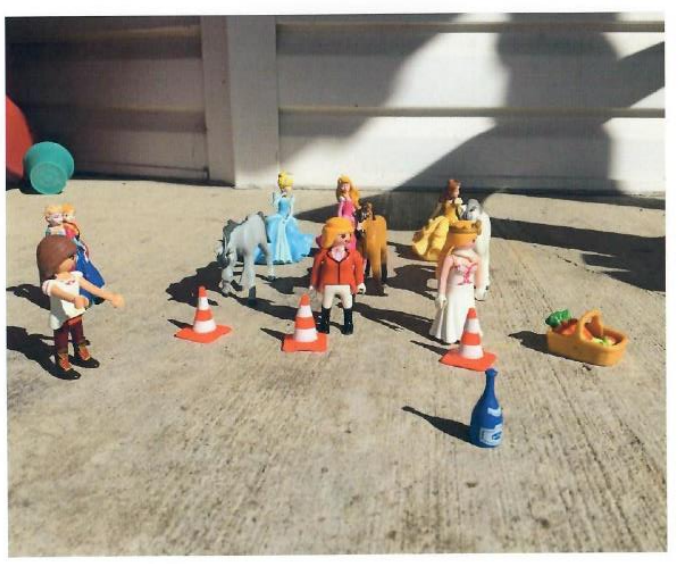

"WHEN WE GET TO GO AND GO RIDE

OUTSIDE...THAT'S THE FUNNEST PART! IN THE SUMMER WE GET TO RIDE...I CAN'T WAIT UNTIL WE CAN RIDE OUTSIDE IN THE OUTSIDE ARENA" - JORDAN 

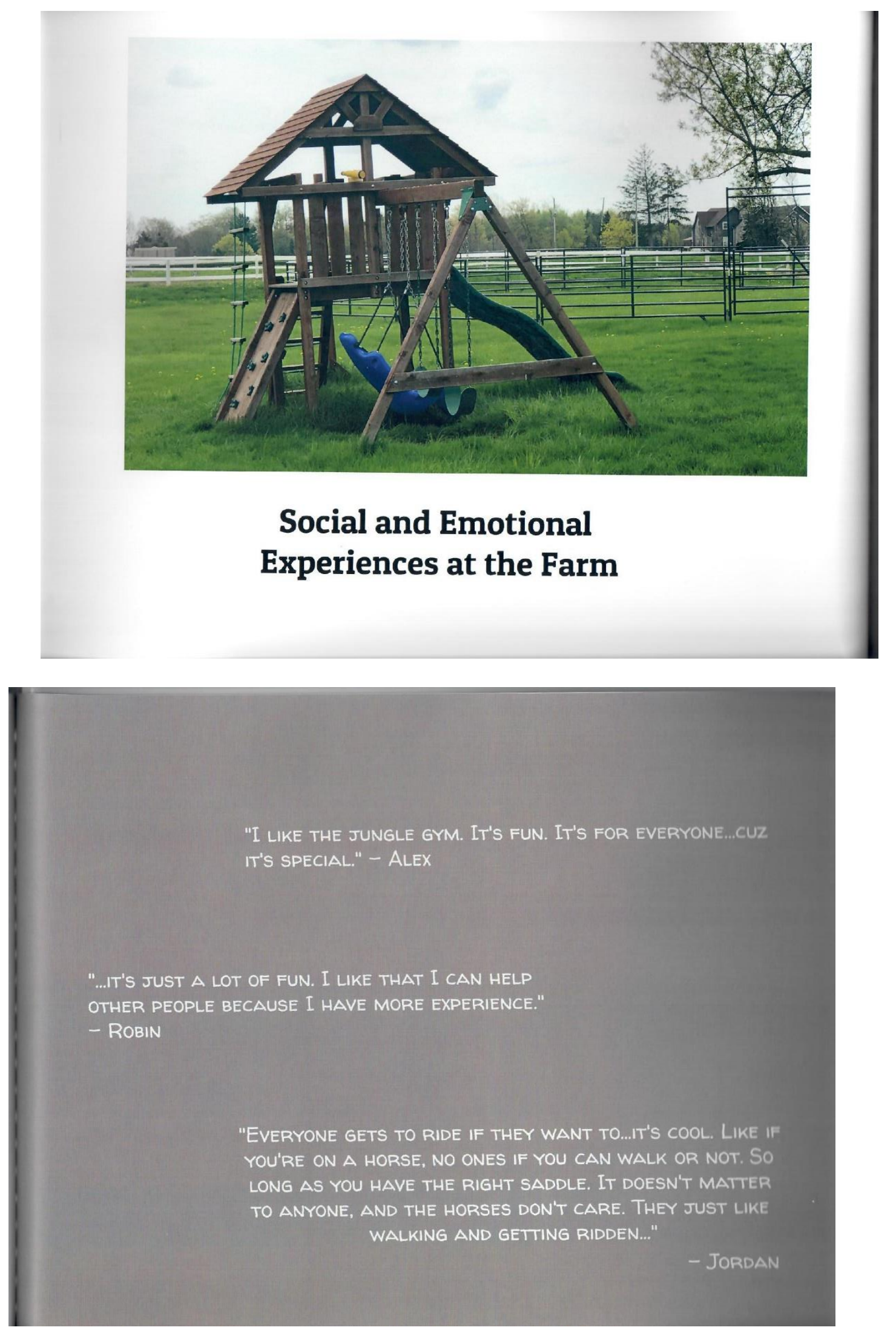


\section{What Would You Change?}

"I WOULD WANT TO HAVE MORE TIME TO PLAY ON

"SOMETIMES WHEN I RIDE IT GETS REALLY THE JUNGLE GYM AND DO BUMPY...THAT CAN MAKE ME SORE" - ALEX

"I DON'T ALWAYS GET TO TELL HER SECRETS CUZ THERE'S ALWAYS SOMEONE THERE...IT GETS BUSY. PEOPLE ARE ALWAYS AROUND." - TAYLOR

"I WANT MY FRIENDS TO COME HERE TOO. I THINK THEY'D LIKE IT A LOT." JAMIE OTHER THINGS AT THE FARM" - ALEX

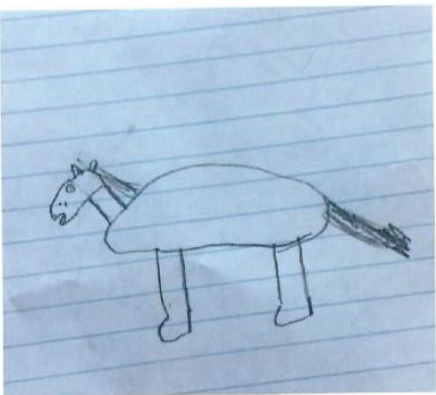

"I THINK IT WOULD BE BETTER IF WE GOT TO GO OUTSIDE MORE. BUT IT'S BEEN HARD TO DO THAT BECAUSE IT'S BEEN RAINING A LOT AND EVERYTHING'S ALL MUDDY." - JORDAN

\section{Connecting to Life Outside of the Farm}

\section{At School}

JAMIE: ...MY FRIENDS WOULD LIKE IT HERE. AND THEY'RE COOL. THEY WOULDN'T BE MEAN OR ANYTHING TO ANYONE."

ERIN: DO YOU HAVE ANY MEAN PEOPLE IN YOUR LIFE?

JAMIE: WELL, LIKE SOMETIMES. LIKE SOMETIMES I HAVE TO TURN MY DESK TO THE WALL IN CLASS, SO KIDS MAKE FUN OF ME FOR THAT, OR THINK I'M WEIRD. BUT IT'S NOT BAD. WE'RE NOT SUPPOSED TO "I COULD LIKE RIDE TO SCHOOL, LIKE NOT ON THE BUS, ON BUTTERCUP, AND I WOULD GET TO RIDE AND BE IN CHARGE AND NO ONE ELSE COULD....LIKE THEN MY TEACHER WOULD LET ME DO STUFF CUZ SHE COULD SEE I COULD LIKE RIDE, SO I CAN DO OTHER STUFF TOO." - ROBIN BULLY PEOPLE. BULLYING IS WRONG, BUT LIKE SOMETIMES IT HAPPENS ANYWAYS. 


\section{So What?}

THE FARM IS A SAFE SPACE TO BE WHO YOU ARE. EVERYONE ACCEPTS YOU FOR YOU

YOU CAN MAKE FRIENDS AT THE FARM AND HAVE FRIENDSHIPS WITH THE HORSES

HORSES CAN HELP YOU CLAM DOWN AND FEEL GOOD
THERE'S A SENSE OF BELONGING AT THE FARM THAT HELPS WITH WELL-BEING

BEING INCLUDED MEANS MORE THAN BEING ABLE TO MOVE AROUND, IT'S ABOUT PARTICIPATING AND GETTING CHANCES TO BE A LEADER

HORSES CAN MAKE YOU FEEL BETTER AND THINK BETTER ABOUT YOURSELF

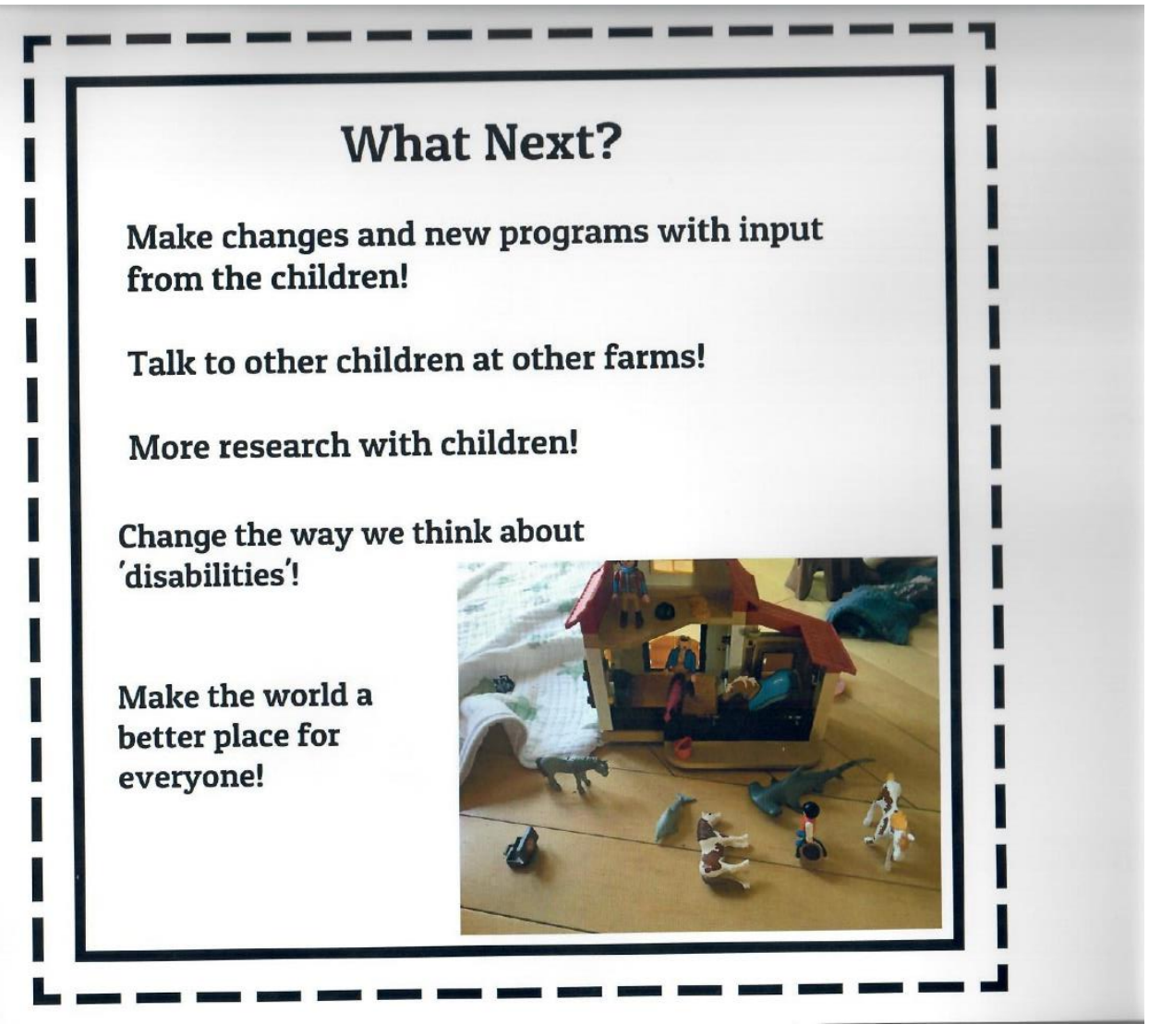




\section{THANK YOU!}

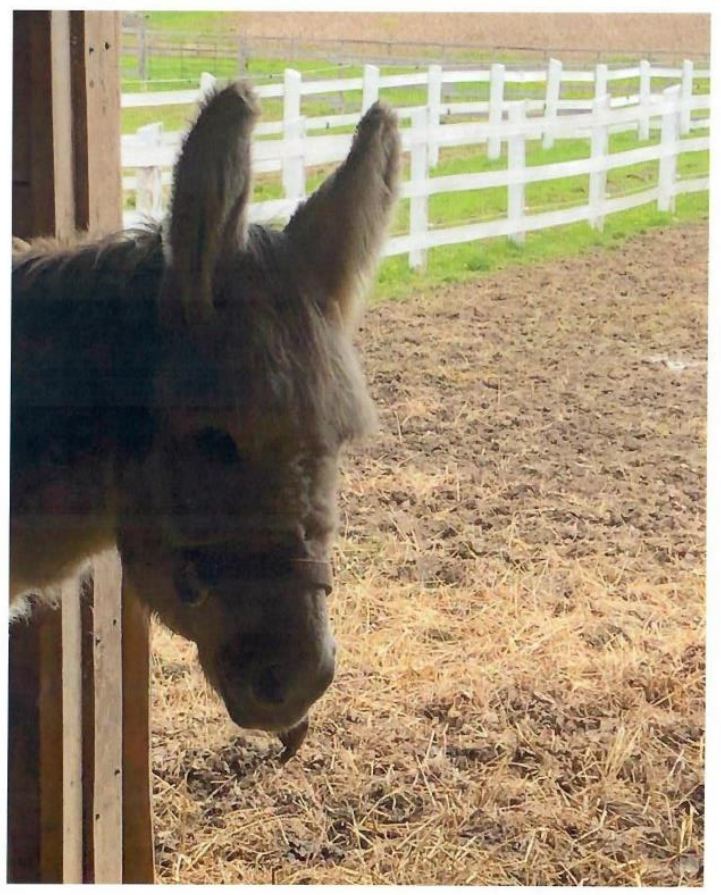




\section{References}

Albanese, P. (2009;2010;). The missing child in canadian sociology: Is it time for change? Jeunesse: Young People, Texts, Cultures, 1(2), 136-146. doi:10.1353/jeu.2010.0023

Anderson, S., \& Meints, K. (2016). Brief report: The effects of equine-assisted activities on the social functioning in children and adolescents with autism spectrum disorder. Journal of Autism and Developmental Disorders, 46(10), 3344-3352. doi:10.1007/s10803-016 2869-3

Anestis, M. D., Anestis, J. C., Zawilinski, L. L., Hopkins, T. A., \& Lilienfeld, S. O. (2014). Equine-Related treatments for mental disorders lack empirical support: A systematic review of empirical investigations. Journal of Clinical Psychology, 70(12), 1115-1132. doi:10.1002/jclp.22113

Angsupaisal, M., Visser, B., Alkema, A., Meinsma-van der Tuin, M., Maathuis, C. G. B., Reinders-Messelink, H., \& Hadders-Algra, M. (2015). Therapist-designed adaptive riding in children with cerebral palsy: Results of a feasibility study. Physical Therapy, 95(8), 1151-1162. doi:10.2522/ptj.20140146

Barnikis, T. (2015). Children's perceptions of their experiences in early learning environments: An exploration of power and hierarchy. Global Studies of Childhood 5(3). p291-304. doi: $10.1177 / 2043610615597148$

Bartholomaeus, C., Gregoric, C., \& Krieg, S. (2016). Young children as active citizens in local government: Possibilities and challenges from an Australian perspective. International Journal of Early Childhood, 48(1), 79-93. 
Bixler, R. D., \& Floyd, M. F. (1997). Nature is scary, disgusting, and uncomfortable. Environment and Behavior, 29(4), 443-467. doi:10.1177/001391659702900401

Brady, G., Lowe, P., \& Olin Lauritzen, S. (2015). Connecting a sociology of childhood perspective with the study of child health, illness and well-being. Sociology of Health \& Illness, 37(2), 173-183.

Boyd, L., \& Le Roux, M. (2017). 'When he’s up there he’s just happy and content': Parents' perceptions of therapeutic horseback riding. African Journal of Disability, 6, e1-e9. doi:10.4102/ajod.v6i0.307

CAMH. (2019). Mental illness and addiction: Facts and statistics. Retrieved from https://www.camh.ca/en/driving-change/the-crisis-is-real/mental-health-statistics

CanTRA. (2018). Home. Retrieved from https://www.cantra.ca/en/

Carter, B. (2014). Advancing health and well-being through children's rights. Journal of Child Health Care, 18(3), 205-206.

Charach, A., Carson, P., Fox, S., Ali, M. U., Beckett, J., \& Lim, C. G. (2013). Interventions for preschool children at high risk for ADHD: A comparative effectiveness review. Pediatrics, 131(5), e1584-e1604. doi:10.1542/peds.2012-0974

Climie, E. A., \& Mastoras, S. M. (2015). ADHD in schools: Adopting a strengths-based perspective. Canadian Psychology/Psychologie Canadienne, 56(3), 295-300. doi:10.1037/cap0000030

Clark, A. (2011). Multimodal map making with young children: Exploring ethnographic and participatory methods. Qualitative Research, 11(3), 311-330. doi:10.1177/1468794111400532 
Clark, A. (2007). A hundred ways of learning: Gathering children's perspectives of their early childhood environment. Young Children, 62(3), 76-81.

Clark, A. and Moss, P. (2001) Listening to young children: The Mosaic approach, London: National Children's Bureau for the Joseph Rowntree Foundation

Clark, A. (2001). How to listen to very young children: The mosaic approach. Child Care in Practice, 7(4), 333-341. doi:10.1080/13575270108415344

Coholic, D. A. (2011). Exploring the feasibility and benefits of arts-based mindfulness-based practices with young people in need: Aiming to improve aspects of self-awareness and resilience. Child \& Youth Care Forum, 40(4), 303-317. doi:10.1007/s10566-010-9139-x

Coholic, D., Schinke, R., Oghene, O., Dano, K., Jago, M., McAlister, H., \& Grynspan, P. (2019). Arts-based interventions for youth with mental health challenges. Journal of Social Work, 146801731982886. doi: $10.1177 / 1468017319828864$

Denscombe, M. (2010). The good research guide: For small-scale social research projects, $4^{\text {th }}$ edition. Berkshire, England: McGraw-Hill.

Devlieger, P. J. (1999). From handicap to disability: Language use and cultural meaning in the united states. Disability and Rehabilitation, 21(7), 346-354. doi:10.1080/096382899297594

D'Eloia, M. H., \& Price, P. (2018). Sense of belonging: Is inclusion the answer? Sport in Society, 21(1), 91-105. doi:10.1080/17430437.2016.1225819

De Roiste, A., Colette, K., Molcho, M., Gavin, A., \& Gabhainn, S.N. (2012). Is school participation good for children? Associations with health and well-being. Health Education, 112(2), 88-104. 
Di Santo, A., \& Kenneally, N. (2014). A call for a shift in thinking: Viewing children as rights holders in early childhood curriculum frameworks. Childhood Education, 90(6), 395-406. doi:10.1080/00094056.2014.982969

Dockett, S., Perry, B. (2005). 'You need to know how to play safe': Children's experiences of starting school. Contemporary Issues in Early Childhood, 6(1). p4-18.

Donnell, A., Rinkoff, R. (2015). The influence of culture on children's relationship with nature. Children, Youth and Environments, 25(3). pp 62-89. doi:10.7721/chilyoutenvi.25.3.0062

Dougherty, L. R., Leppert, K.,A., Merwin, S.M., Smith, V.C., Bufferd, S.J., \& Kushner, M.R. (2015). Advances and directions in preschool mental health research. Child Development Perspectives, 9(1), 14-19.

Elmac1, D. T., \& Cevizci, S. (2015). Dog-assisted therapies and activities in rehabilitation of children with cerebral palsy and physical and mental disabilities. International Journal of Environmental Research and Public Health, 12(5), 5046-5060. doi:10.3390/ijerph120505046

Ewing, C. A., MacDonald, P. M., Taylor, M., \& Bowers, M. J. (2007). Equine-facilitated learning for youths with severe emotional disorders: A quantitative and qualitative study. Child and Youth Care Forum, 36(1), 59-72. doi:10.1007/s10566-006-9031-x

Fazio, E., Medica, P., Cravana, C., \& Ferlazzo, A. (2013). Hypothalamic-pituitary-adrenal axis responses of horses to therapeutic riding program: Effects of different riders. Physiology \& Behavior, 118, 138-143. doi:10.1016/j.physbeh.2013.05.009

Ferraro, K.F., Schafer, M.H., Wilkinson, L.R. (2015). Childhood disadvantage and health problems in middle and later life: Early imprints on physical health? American Sociological Review, 81(1), 107-133. https://doi.org/10.1177/0003122415619617 
Freeman, and Freeman. (1998). The sociology of childhood and children's rights. The International Journal of Children's Rights, 6(4), 433-444. doi: $10.1163 / 15718189820494175$

Gerlach, A. (2018). Thinking and researching relationally: Enacting decolonizing methodologies with an indigenous early childhood program in Canada. International Journal of Qualitative Methods 17, 1-18.

Giagazoglou, P., Arabatzi, F., Kellis, E., Liga, M., Karra, C., \& Amiridis, I. (2013). Muscle reaction function of individuals with intellectual disabilities may be improved through therapeutic use of a horse. Research in Developmental Disabilities, 34(9), 2442-2448. doi:10.1016/j.ridd.2013.04.015

Gillespie, J. (2012). Being and becoming: Writing children into planning and theory. Planning Theory, 12. 64-80. doi:10.1177/1473095212441696

Grover, S. (2004). Why won't they listen to us?: On giving power and voice to children participating in social research. Childhood, 11(1), 81. doi:10.1177/0907568204040186

Habib, H. A., \& Ali, U. (2015). Efficacy of art therapy in the reduction of impulsive behaviors of children with ADHD co-morbid intellectual disability. Pakistan Journal of Psychology, $46(2)$

Harpur, P. (2012) From disability to ability: Changing the phrasing of the debate. Disability \& Society, 27(3), 325-337.

Heilskov Rytter, M. J., Andersen, L. B. B., Houmann, T., Bilenberg, N., Hvolby, A., Mølgaard, C., . . Lauritzen, L. (2015). Diet in the treatment of ADHD in children-A systematic review of the literature. Nordic Journal of Psychiatry, 69(1), 1-18. doi:10.3109/08039488.2014.921933 
Hull, R. (1998). Defining disability-A philosophical approach. Res Publica, 4(2), 199-210. doi:10.1007/BF02390098

Kalvaitis, D., \& Monhardt, R. M. (2012). The architecture of children's relationships with nature: A phenomenographic investigation seen through drawings and written narratives of elementary students. Environmental Education Research, 18(2), 209. doi:10.1080/13504622.2011.598227

Kelly, M. A., \& Cozzolino, C. A. (2015). Helping at-risk youth overcome trauma and substance abuse through animal-assisted therapy. Contemporary Justice Review, 18(4), 421-434. doi:10.1080/10282580.2015.1093686

Koller, D. (2016). "Kids need to talk too": Inclusive practices for children's health care education and participation. Journal of Clinical Nursing, 26, 2657-2668.

Koller, D., Khan, N., \& Barrett, S. (2015). Pediatric perspectives on diabetes self-care: A process of achieving acceptance. Qualitative Health Research, 25(2), 264-275. doi: $10.1177 / 1049732314551057$

Lane, D., Blank, J., \& Jones, P. (2019). Research with children: Context, power, and representation. The Qualitative Report, 24(4), 693.

Larkin, C. (2014). Enacting children's citizenship: Developing understandings of how children enact themselves as citizens through actions and acts of citizenship. Childhood, 21(1), 7 21.

Leavy, P. (2017). Research design: Quantitative, qualitative, mixed methods, arts-based, and community-based participatory research approaches. The Guilford Press. NY: NY 
Liegghio, M., Nelson, G., Evans, S.D. (2010). Partnering with children with mental health issues: Contributions of a sociology of childhood perspective to participatory action research. Am J Community Psychol 46. 84-99 doi 10.007/s10464-010-9323-z

Linder, L. A., \& Seitz, M. (2017). Through their words: Sources of bother for hospitalized children and adolescents with cancer. Journal of Pediatric Oncology Nursing, 34(1), 5164. doi: $10.1177 / 1043454216631308$

Maber-Aleksandrowicz, S., Avent, C., \& Hassiotis, A. (2016). A systematic review of animal assisted therapy on psychosocial outcomes in people with intellectual disability. Research in Developmental Disabilities, 49-50, 322-338. doi:10.1016/j.ridd.2015.12.005

Maich, K., Davies, A. W. J., \& van Rhijn, T. (2019). A relaxation station in every location. Intervention in School and Clinic, 54(3), 160-165. doi:10.1177/1053451218767916

Manning, J. C., Hemingway, P., \& Redsell, S. A. (2017). Stories of survival: Children's narratives of psychosocial well-being following paediatric critical illness or injury. Journal of Child Health Care: For Professionals Working with Children in the Hospital and Community, 21(3), 236.

Moharreri, F., Khorsand Vakilzadeh, A., Soltanifar, A., Abdollahian, E., Eslami, S., \& Nahidi, M. (2018). Efficacy of adding acupuncture to methylphenidate in children and adolescents with attention deficit hyperactivity disorder: A randomized clinical trial. European Journal of Integrative Medicine, 22, 62-68. doi:10.1016/j.eujim.2018.08.003

Noble, H., \& Mitchell, G. (2016). What is grounded theory? Evidence Based Nursing, 19(2), 34 35. doi:10.1136/eb-2016-102306

Normand, S., Schneider, B. H., Lee, M. D., Maisonneuve, M., Chupetlovska-Anastasova, A., Kuehn, S. M., \& Robaey, P. (2013). Continuities and changes in the friendships of 
children with and without ADHD: A longitudinal, observational study. Journal of Abnormal Child Psychology, 41(7), 1161-1175. doi:10.1007/s10802-013-9753-9

Nurenberg, J. R., Schleifer, S. J., Shaffer, T. M., Yellin, M., Desai, P. J., Amin, R., . . . Montalvo, C. (2015). Animal-assisted therapy with chronic psychiatric inpatients: Equine-assisted psychotherapy and aggressive behavior. Psychiatric Services, 66(1), 80 86. doi:10.1176/appi.ps.201300524

Palley, L. S., O'Rourke, P. P., \& Niemi, S. M. (2010). Mainstreaming animal-assisted therapy. ILAR Journal, 51(3), 199-207. doi:10.1093/ilar.51.3.199

Poulou, M.S. (2015). Emotional and behavioral difficulties in preschool. Journal of Child and Family Studies, 24, 225-236.

Prout, A. \& James, A. (1997). A new paradigm for the sociology of childhood? Provenance, promise and problems. In A. Prout \& A. James (Eds.), Constructing and reconstructing childhood: Contemporary issues in the sociological study of childhood (2nd ed.) (pp. 732). London, England: Falmer Press.

Prout, A. \& A. James (1990) ‘A New Paradigm for the Sociology of Childhood? Provenance, Promise and Problems', in A. James and A. Prout (eds) Constructing and Deconstructing Childhood: Contemporary Issues in the Sociological Study of Childhood, pp. 7-34. New York: The Falmer Press.

Raby, R., Lehmann, W., Easterbrook, R., \& Helleiner, J. (2018). "I'll be more prepared than most people": Very young canadian workers talking about their first jobs. Childhood, 25(2), 237-252. doi:10.1177/0907568218758148 
Reiss, F. (2013). Socioeconomic inequalities and mental health problems in children and adolescents: A systematic review. Social Science \& Medicine, 90, 24-31. doi:10.1016/j.socscimed.2013.04.026

Robrecht, L. C. (1995). Grounded theory: Evolving methods. Qualitative Health Research, 5(2), 169-177. doi:10.1177/104973239500500203

Smith-Osbourne, A., Selby, A. (2010). Implications of the Literature on Equine-Assisted Activities for Use as a Complementary Intervention in Social Work Practice with Children and Adolescents. Child and Adolescent Social Work Journal, 27(1), 291-307.

Sönmez, S., \& Ceylan, B. (2017). Teachers' perceptions of well-being and involvement in preschool children. Early Child Development and Care, 187(1), 35-44.

Srinivasan, S. M., Cavagnino, D. T., \& Bhat, A. N. (2018). Effects of equine therapy on individuals with autism spectrum disorder: A systematic review. Review Journal of Autism and Developmental Disorders, 5(2), 156-175. doi:10.1007/s40489-018-0130-z

Srinivasan, S. M., \& Bhat, A. N. (2013). A review of "music and movement" therapies for children with autism: Embodied interventions for multisystem development. Frontiers in Integrative Neuroscience, 7, 22.

Stienstra, D. (2018). Canadian disability policies in a world of inequalities. Societies, 8(2), 36. doi:10.3390/soc8020036

Stienstra, D. (2015). Trumping all? disability and girlhood studies. Girlhood Studies, 8(2), 54. doi:10.3167/ghs.2015.080205

Stienstra, D., \& Ashcroft, T. (2010). Voyaging on the seas of spirit: An ongoing journey towards understanding disability and humanity. Disability \& Society, 25(2), 191-203. doi:10.1080/09687590903534411 
Tan, V. X., \& Simmonds, J. G. (2018). Parent perceptions of psychosocial outcomes of equine assisted interventions for children with autism spectrum disorder. Journal of Autism and Developmental Disorders, 48(3), 759-769. doi:10.1007/s10803-017-3399-3

Te Meerman, S., Batstra, L., Grietens, H., \& Frances, A. (2017). ADHD: A critical update for educational professionals. International Journal of Qualitative Studies on Health and Well-being, 12(1), 1298267-7. doi:10.1080/17482631.2017.1298267

The Children's Society. (2018). The good childhood report. Retrieved from http://www.childrenssociety.org.uk.

Uchiyama, H., Ohtani, N., \& Ohta, M. (2011). Three-dimensional analysis of horse and human gaits in therapeutic riding. Applied Animal Behaviour Science, 135(4), 271-276. doi:10.1016/j.applanim.2011.10.024

United Nations. (1991). Convention on the Rights of the Child. Human Rights Program Department of Canadian Heritage.

van Rhijn, T., Osborne, C., Ranby, S., Maich, K., Hall, C., Rzepecki, L., \& Hemmerich, A. (2019). Peer play in inclusive child care settings: Assessing the impact of stay, play, \& talk, a peer-mediated social skills program. Child Care in Practice, 1-15. doi:10.1080/13575279.2019.1588707

Wang, M. \& Brown, R. (2009). Family quality of life: A framework for policy and social service provision to support families of children with disabilities. Journal of Family Social Work, $12,144-167$.

White-Lewis, S., Russell, C., Johnson, R., Cheng, A. L., \& McClain, N. (2017). Equine-assisted therapy intervention studies targeting physical symptoms in adults: A systematic review. Applied Nursing Research, 38, 9-21. doi:10.1016/j.apnr.2017.08.002 
Wilkes-Gillan, S., Bundy, A., Cordier, R., Lincoln, M., \& Hancock, N. (2015). Parents’ perspectives on the appropriateness of a parent-delivered intervention for improving the social play skills of children with ADHD. British Journal of Occupational Therapy, 78(10), 644-652. doi:10.1177/0308022615573453

Wilson, K., Buultjens, M., Monfries, M., \& Karimi, L. (2017). Equine-assisted psychotherapy for adolescents experiencing depression and/or anxiety: A therapist's perspective. Clinical Child Psychology and Psychiatry, 22(1), 16.

Wood, B. E. (2010). Youth participation in society: Everyday citizenship perspectives from young people in New Zealand. New Zealand Sociology, 25(2), 103-124. 